\title{
Multidrug resistance in fungi: regulation of transporter-encoding gene expression
}

\author{
Sanjoy Paul and W. Scott Moye-Rowley* \\ Department of Molecular Physiology and Biophysics, Carver College of Medicine, University of lowa, lowa City, IA, USA
}

\section{Edited by:}

Isabel Sá-Correia, Instituto Superior

Técnico, Portugal

\section{Reviewed by:}

Miguel Cacho Teixeira, Technical

University of Lisbon, Portugal

Frederic Devaux, Universite Pierre et

Marie Curie, France

*Correspondence:

W. Scott Moye-Rowley,

Department of Molecular Physiology and Biophysics, Carver College of

Medicine, University of lowa,

6-530 Bowen Science Building,

lowa City, IA 52242, USA

e-mail:scott-moye-rowley@

uiowa.edu

A critical risk to the continued success of antifungal chemotherapy is the acquisition of resistance; a risk exacerbated by the few classes of effective antifungal drugs. Predictably, as the use of these drugs increases in the clinic, more resistant organisms can be isolated from patients. A particularly problematic form of drug resistance that routinely emerges in the major fungal pathogens is known as multidrug resistance. Multidrug resistance refers to the simultaneous acquisition of tolerance to a range of drugs via a limited or even single genetic change. This review will focus on recent progress in understanding pathways of multidrug resistance in fungi including those of most medical relevance. Analyses of multidrug resistance in Saccharomyces cerevisiae have provided the most detailed outline of multidrug resistance in a eukaryotic microorganism. Multidrug resistant isolates of S. cerevisiae typically result from changes in the activity of a pair of related transcription factors that in turn elicit overproduction of several target genes. Chief among these is the ATP-binding cassette (ABC)-encoding gene PDR5. Interestingly, in the medically important Candida species, very similar pathways are involved in acquisition of multidrug resistance. In both $C$. albicans and C. glabrata, changes in the activity of transcriptional activator proteins elicits overproduction of a protein closely related to $S$. cerevisiae Pdr5 called Cdr1. The major filamentous fungal pathogen, Aspergillus fumigatus, was previously thought to acquire resistance to azole compounds (the principal antifungal drug class) via alterations in the azole drug target-encoding gene cyp51A. More recent data indicate that pathways in addition to changes in the cyp51A gene are important determinants in $A$. fumigatus azole resistance. We will discuss findings that suggest azole resistance in $A$. fumigatus and Candida species may share more mechanistic similarities than previously thought.

Keywords: multidrug resistance, transcription, fungal pathogens, $A B C$ transporters, transcription factors, regulation of gene expression

\section{INTRODUCTION}

Scientifically, one of the most attractive features of the fungal microorganisms is their striking biological similarity with mammalian cells. This similarity has led to their extensive use as models for basic properties of eukaryotic cells but also illustrates one of the important challenges in dealing with fungal pathogens. Development of antifungal drugs has been slowed by the close relationship between the fundamental cell biology of a fungus and a typical mammalian cell. Early antifungal drugs like amphotericin B were efficacious in treating fungal infections but suffer from high toxicity to the patient (Moen et al., 2009).

More recently developed drugs like the azoles and echinocandins, exhibit better specificity for pathogens but their very success has led to the selection of fungi that are highly tolerant of these antifungal agents (recently discussed in Brown et al., 2012). Azole drugs are the primary antifungal drug used in the clinic and infections associated with azole resistant fungi have dramatically lowered survival rates compared to those associated with azole susceptible organisms (reviewed in Pfaller, 2012). Resistance to azole drugs emerges by two different routes: direct and indirect mechanisms. Direct changes involve changes in the enzyme that is targeted by azole compounds, lanosterol $14 \alpha$ demethylase
(See Kristan and Rizner, 2012 for a recent review). This enzyme is encoded by the ERG11 gene in Saccharomyces cerevisiae with azole resistant alleles found to either change the sequence of the protein and/or alter expression levels of this gene product. While these direct changes can be found in S. cerevisiae and pathogenic yeast, a common form of azole resistance arises via indirect means. Most typically, selection for azole resistant yeast elicits isolation of strains that overproduce ATP-binding cassette $(\mathrm{ABC})$ transporter proteins. These $\mathrm{ABC}$ transporter proteins act to efflux azole drugs from the cell and prevent accumulation of otherwise toxic levels (recently reviewed in Prasad and Goffeau, 2012).

$\mathrm{ABC}$ transporter overproduction is a well-known cause of drug resistance in mammalian cells (See Holohan et al., 2013 for a recent discussion). Cancer patients undergoing chemotherapeutic treatment are often found to eventually develop tumors that are termed multidrug resistant. These in vivo selected tumors are refractory to growth inhibition caused by a wide range of different chemotherapeutics, even drugs to which the patient was not previously exposed (Szakacs et al., 2006). Multidrug resistant tumors can be associated with gene amplification events that lead to an increase in copy number of genes encoding $\mathrm{ABC}$ transporters 
with a concomitant elevation in protein level (Ambudkar et al., 2003).

In fungal cells, multidrug resistant cells can easily be selected. These mutant strains do not usually have increased gene dosage but rather possess increased expression of $\mathrm{ABC}$ transporterencoding genes (reviewed in Sanglard et al., 2009; Morschhauser, 2010). Elevated gene expression leads to an increase in the protein level of these membrane transporters with accompanying broad range drug tolerance. In every fungus that has been studied, $A B C$ transporters are able to influence azole resistance making this a key issue in treatment of fungal infections.

Given the importance of the level of $\mathrm{ABC}$ transporter gene expression in development of azole resistance, their regulation has been the focus of extensive investigation. These studies have led to the identification of dedicated transcription factors dedicated to coordination of their expression with other genes in fungi. Our most detailed picture of the network of transcriptional regulation and multidrug resistance gene is available for the yeast Saccharomyces cerevisiae. This network has served as a starting point for the analysis of similar systems in pathogenic fungi and will be discussed below.

\section{TRANSCRIPTIONAL CIRCUITRY CONTROLLING PLEIOTROPIC DRUG RESISTANCE IN $S$. CEREVISIAE \\ $\mathrm{Zn}_{2} \mathrm{Cys}_{6}$ ZINC CLUSTER-CONTAINING FACTORS}

The first transcription factor discovered to be a determinant of multidrug resistance in S. cerevisiae was appropriately designated Pdr1 (Saunders and Rank, 1982). Early genetic work pointed to the existence of dominant alleles of the PDR1 gene as conferring resistance to a wide range of different toxic compounds (Rank and Bech-Hansen, 1973; Rank et al., 1975, 1976). This broad range resistance phenotype in S. cerevisiae was designated pleiotropic drug resistance (Pdr) and is functionally analogous to the multidrug resistance seen in mammalian cells and other fungi. This early work has been the subject of several reviews (Balzi and Goffeau, 1995; Bauer et al., 1999; Gulshan and Moye-Rowley, 2007) and will only be outlined here.

Isolation of the cloned PDR1 gene by Balzi et al. (1987) led to rapid advances in understanding of the molecular basis of the Pdr phenotype in S. cerevisiae. The DNA sequence of PDR1 led to two important findings. First, this gene encoded a $\mathrm{Zn}_{2} \mathrm{Cys}_{6}$ cluster-containing transcription factor similar to the previously described Gal4 (Johnston, 1987). Second, sequence of a dominant, multidrug resistant allele of PDR1 demonstrated that this hypermorphic or gain-of-function (GOF) behavior of Pdr1 was caused by a single amino acid substitution mutation in the central region of the protein. Many different amino acid substitution mutations were eventually discovered that caused Pdr1 to exhibit elevated, constitutive transcriptional activation of target gene expression (Carvajal et al., 1997).

The discovery that Pdr1 was a transcriptional regulator led to work from multiple laboratories to identify genes that were more directly responsible for the observed multidrug resistance phenotype. The first major class of Pdr1 target genes contained several different loci encoding $\mathrm{ABC}$ transporter proteins (Balzi et al., 1994; Bissinger and Kuchler, 1994; Hirata et al., 1994a; Katzmann et al., 1995; Mahe et al., 1996). These proteins were typically found in the plasma membrane and thought to act as broad specificity, drug efflux pumps as previously seen in mammalian tumor cells (Gottesman et al., 1995). The PDR5 locus was found to possess unique central importance among the $\mathrm{ABC}$ transporterencoding genes as the expression level of this gene is the highest of the drug resistance-related $\mathrm{ABC}$ transporters and mutants lacking this gene exhibit profound drug hypersensitivities (Leppert et al., 1990; Decottignies et al., 1994). PDR5 transcription was strongly elevated in cells containing hyperactive PDR1 dominant alleles through the binding of the transcriptional regulatory protein to three sites in the promoter region (Katzmann et al., 1996). These sites are referred to as Pleiotropic Drug Response Elements or PDREs and have been found upstream of the majority of Pdr1-regulated genes.

A factor closely related to Pdr1 was discovered during genome sequencing experiments and designated PDR3 (Delaveau et al., 1994). GOF PDR3 alleles similar to those described for PDR1 were isolated and elevated PDR5 transcription and drug resistance found to occur in these strains (Dexter et al., 1994; Nourani et al., 1997; Simonics et al., 2000). Generally speaking, the phenotypic effects of activated alleles of $P D R 1$ and $P D R 3$ are very similar. However, a feature unique to the PDR3 gene was the presence of two PDREs in its promoter (Delahodde et al., 1995). This autoregulatory input was found to be essential for normal function of $P D R 3$ and is a key component for the regulated expression of this gene (Delahodde et al., 1995; Zhang and Moye-Rowley, 2001).

Along with Pdr1 and Pdr3, several other zinc clustercontaining transcription factors have been associated with the Pdr phenotype. The first of these, Yrr1, was recovered in a screen for tolerance to a cell cycle inhibitor called reveromycin A (Cui et al., 1998). Later work indicated that Yrrl was both autoregulated and transcriptionally induced by Pdr1/Pdr3 activity (Zhang et al., 2001). Several laboratories discovered that YRR1 mutants could be recovered that exhibited high constitutive transcriptional activation as previously discussed for similar alleles in PDR1 and PDR3 (Cui et al., 1998; Zhang et al., 2001; Keeven et al., 2002; Le Crom et al., 2002). Two homologs of Yrr1 have also been studied: Yrm1 (Lucau-Danila et al., 2003) and Pdr8 (Hikkel et al., 2003).

\section{NON-TRANSPORTER TARGETS GENES OF PDR1/PDR3}

While the first genes identified that were controlled by the Pdr regulon were $\mathrm{ABC}$ transporters, more recent data make it clear that many different types of proteins are encoded by Pdr1/Pdr3 target genes (Derisi et al., 2000; Devaux et al., 2001, 2002; Traven et al., 2001). These other classes of proteins include 7 transmembrane domain-containing membrane proteins (Rsb1, Rta1) (Kihara and Igarashi, 2004; Panwar and Moye-Rowley, 2006; Kolaczkowska et al., 2012), enzymes involved in sphingolipid biosynthesis (Hallstrom et al., 2001; Kolaczkowski et al., 2004), phospholipid transfer (Van Den Hazel et al., 1999), and other proteins of poorly characterized function. Given the roles for many of these other proteins in lipid homeostasis it is reasonable to propose that the control of lipids has an important effect on drug resistance. Evidence in support of this notion is accumulating in S. cerevisiae and other fungi (Hallstrom et al., 2001; Kolaczkowski et al., 2004; Prasad et al., 2005). While it is important to recognize 
that the Pdr response involves more than simply transporter genes, these are the best understood in terms of their role in drug resistance. We will focus on the control of transporter genes in this review.

\section{BASIC REGION-LEUCINE ZIPPER-CONTAINING TRANSCRIPTION FACTORS}

One of the earliest transcriptional regulators found to influence Pdr was the basic region-leucine zipper (bZip)-containing factor Yap1. Yap1 was isolated in a high-copy-plasmid suppressor screen as PDR4, a gene capable of elevating resistance to cycloheximide and the branched chain amino acid biosynthesis inhibitor sulfometuron methyl (Leppert et al., 1990). Later work demonstrated that YAP1 and PDR4 were allelic (Hussain and Lenard, 1991) and that Yap1 did not appear to act via PDR5 (Dexter et al., 1994). Work from several labs demonstrated that the bZip-containing protein Cad1/Yap2 also elevated drug resistance although this effect could only be seen when this protein was overproduced (Bossier et al., 1993; Wu et al., 1993; Hirata et al., 1994b). Similarly, high dosages of the Yap1 homologs Yap5 and Yap6 also conferred resistance to several different drugs (Fernandes et al., 1997; Furuchi et al., 2001).

While there are clear links between the bZip-containing factors and drug resistance, most of the drug resistance effects shown by this group of transcription factors occur when these proteins are overproduced. Disruption mutations rarely exhibit hypersensitivity suggesting either that extensive redundancy exists between these family members or that the normal role of these factors is not to modulate drug resistance. Yap1 is the best understood of these bZip-containing factors in terms of its regulation (reviewed in Toone et al., 2001; Moye-Rowley, 2003a; Rodrigues-Pousada et al., 2004). Loss of the YAP1 gene has a profound sensitivity to oxidative stress (Schnell et al., 1992; Kuge and Jones, 1994) but little to no consequence on drug resistance (Leppert et al., 1990; Wu et al., 1993; Alarco et al., 1997). An exception to this rule is provided by drugs such as the agrochemical mancozeb that proceed via an oxidative mechanism in which physiological levels of Yap1 are required for normal resistance (Teixeira et al., 2008). Drugs that act through a mechanisms that does not invoke an oxidative stress response typically are insensitive to the presence of Yap1 expressed at normal gene dosage. Yap1 has been thoroughly documented as an important regulator of major facilitator superfamily (MFS) gene expression in the case of FLR1 (Alarco et al., 1997) and ATR1 (Coleman et al., 1997). Activation of expression of these genes is likely to explain many of the effects of this transcription factor on drug resistance although little evidence exists that Yap1-dependent transactivation can be stimulated by the presence of drugs. Extensive documentation exists for activation of Yap1 function upon oxidative stress (Kuge et al., 1997; Coleman et al., 1999; Delaunay et al., 2000, 2002). We will focus our discussion on the $\mathrm{Zn}_{2} \mathrm{Cys}_{6}$ zinc cluster-containing proteins as the paradigms for drug-induced transcriptional activation in S. cerevisiae (and likely other fungi as well).

\section{CONTROL OF TRANSCRIPTIONAL ACTIVATION IN S. CEREVISIAE MULTIDRUG RESISTANCE}

The identification of alleles of PDR 1 as dominant, GOF mutations suggested the possibility of regulatory modulation of the Pdr1 protein. The determination that Pdr1 and Pdr3 were closely related $\mathrm{Zn}_{2} \mathrm{Cys}_{6}$ zinc cluster-containing transcription factors also argued that these proteins were most likely to be indirect determinants of multidrug resistance via their regulation of direct effectors of this phenotype (such as PDR5). Sequence analysis of a large number of these hyperactive mutant alleles of PDR1 and PDR3 demonstrated that this multidrug resistant phenotype was routinely caused by single amino acid substitutions in three main regions of these factors (Dexter et al., 1994; Carvajal et al., 1997; Nourani et al., 1997; Simonics et al., 2000). A model of Pdr1 structure is shown in Figure 1. Early analyses of these GOF alleles indicated that target genes were overexpressed in the presence of the mutant forms of the transcription regulators. For example, PDR5 mRNA levels are increased by roughly 10-fold in the presence of a PDR1 GOF allele compared to levels driven by the wild-type gene (Meyers et al., 1992). This correlates well with the observed increment in drug resistance.

While the characterization of the GOF mutants supported the view that the factors regulating Pdr were under some type of regulatory control, these alleles represent chronic functional alterations in these transcription factors. Here we will summarize more recent progress in elaboration of mechanisms controlling activity of either wild-type Pdr1 or Pdr3. To date, regulatory inputs to these two closely related proteins are unique to each factor and will be considered separately.

\section{PDR1 REGULATION}

The first example of a trans-factor influencing Pdr1 activity came from the identification of the Hsp70 protein Ssz1 (originally Pdr13) as a positive regulator of Pdr1 function when overproduced (Hallstrom et al., 1998). Later work demonstrated that this Hsp70 was primarily associated with the ribosome (Hallstrom and Moye-Rowley, 2000a) and has an important role in folding of nascent polypeptide chains (Gautschi et al., 2001). Recently, these findings have been extended with the determination that the dnaJ protein Zuol (partner of the dnaK Ssz1 Michimoto et al., 2000) can also stimulate Pdr1 function, possibly by direct binding to

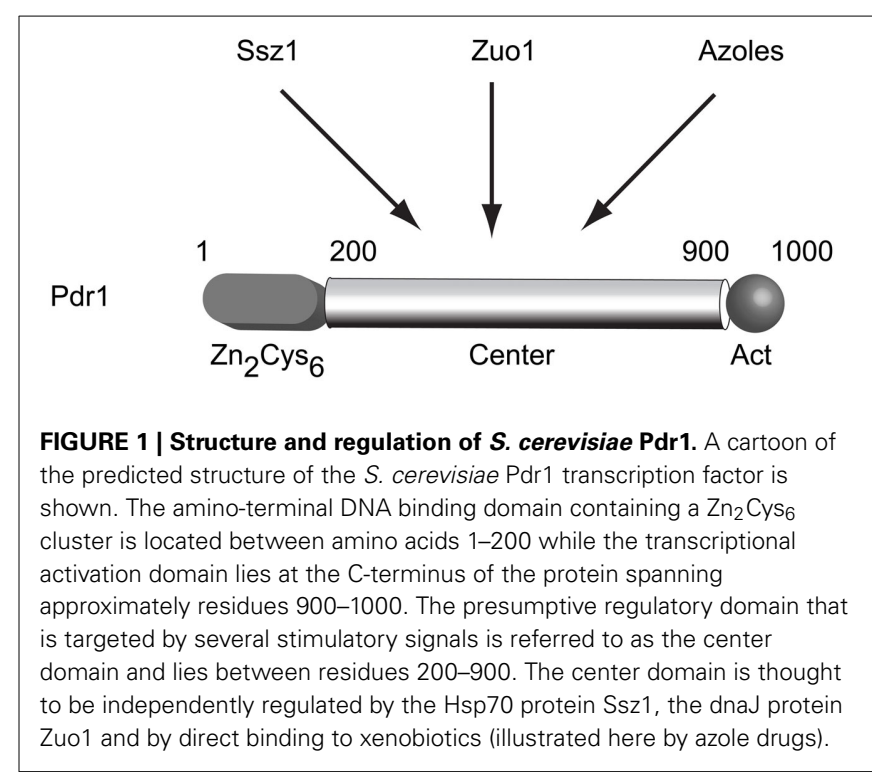


this transcription factor (Eisenman and Craig, 2004). Zuol contains a short C-terminal region of 13 residues that is necessary and sufficient to induce Pdr1 transcriptional activity (Ducett et al., 2013).

Both Zuol and Ssz1 are present at much higher levels than Pdr1 and are thought to have their primary function at the ribosome (Gautschi et al., 2001). Work from the Craig lab has argued that the Zuo1/Ssz1 protein pair can independently activate Pdr1 and are found directly associated with this factor on target promoters (Prunuske et al., 2012). As these findings suggest, the action of Zuo1/Ssz1 in terms of control of Pdr1 activity represents an extra-ribosomal function of these proteins (Eisenman and Craig, 2004). Despite significant effort, the molecular rationale linking activity of these chaperone proteins to Pdr1 remains obscure. An interesting possible tie between Pdr1 and protein folding/degradation came from the finding that the gene encoding the key proteasomal transcriptional regulator Rpn4 is a transcriptional target of Pdr1 (Devaux et al., 2001; Owsianik et al., 2002). Activation of Pdr1 function by Sszl can suppress defects in endoplasmic reticulum-associated degradation (Bosis et al., 2010) further strengthening the association of $\mathrm{Pdr} 1$ activity with protein homeostasis.

An intriguing model for Pdr1 (and Pdr3) to act as xenobiotic receptor proteins came from studies led by Anders Näär (Thakur et al., 2008). This work provided evidence that the central regions of both these transcription factors could directly bind radioactive fluconazole and that this antifungal drug triggered an increase in Pdr1/3-dependent gene expression. These data support the attractive notion that $\mathrm{Pdr} 1 / 3$ were normally held in a low activity state but could be remodeled in the presence of an appropriate ligand to a more potent transcriptional stimulator.

The simplicity and precedence of this model make it a compelling view for the regulation of $\mathrm{Pdr} 1 / 3$ in physiology. It is still difficult to rationalize why overproduction of either Pdr1 or Pdr3, in the absence of any exogenous drug, can lead to increased gene expression (see for example: Katzmann et al., 1994; Carvajal et al., 1997). If activation of these factors required the presence of a small molecule, then overproduction would not be expected to lead to increase downstream gene expression. In cases where a small molecule is known to be required for activity of a zinc cluster-containing transcription factor, overproduction of the factor leads to downstream repression of gene expression. Examples of this behavior include the heme-dependent activator Hap1 (Zhang et al., 1998) and the leucine biosynthetic activator protein Leu3 (Sze et al., 1993). The genetic behavior of Pdr1/3 seem more easily fit to a situation in which a negative regulatory system is outcompeted when these proteins are overproduced. Further experiments are required to dissect the mechanism of Pdr1/3 control via by small molecules.

\section{PDR3 REGULATION}

Although hyperactive alleles of PDR3 were identified at the inception of the study of the Pdr network in S. cerevisiae (Dexter et al., 1994), early analyses of the contribution of Pdr3 to drug resistance suggested that this factor was a less important contributor to transcriptional control than its homolog Pdr1 (Delaveau et al., 1994; Katzmann et al., 1994). Screening a library of random transposon-induced null mutations to identify negative regulators of PDR5 expression uncovered an array of gene involved in maintaining the mitochondrial genome (Hallstrom and Moye-Rowley, 2000b). Loss of mitochondrial DNA $\left(\rho^{0}\right)$ led to a strong induction of PDR5 gene expression that was strictly Pdr3-dependent. This was the first example of a situation in yeast in which the level of PDR5 expression and associated drug resistance rivaled those seen in the presence of a hyperactive allele of either PDR1 or PDR3.

Characterization of the requirements for this mitochondrial signal to trigger Pdr3 induction demonstrated that of the many types of mutations compromising mitochondrial function, only those that also elicited loss of mitochondrial DNA were able to elevate Pdr3 function (Zhang and Moye-Rowley, 2001). The autoregulatory loop of $P D R 3$ transcription was also essential for the $\rho^{0}$ response. However, driving Pdr3 expression from the PDR1 promoter was still able to produce a $\rho^{0}$-dependent induction in drug resistance (Hallstrom and Moye-Rowley, 2000b) arguing that Pdr3 was regulated post-translationally. Together, these findings suggest that a mitochondrial genome-dependent signal leads to a release of Pdr3 from some negative regulatory system. This in turn allows Pdr3 to engage with its own promoter and positively autoregulate transcription. Pdr3 regulation is diagrammed in Figure 2.

Further genetic analyses identified several other factors that are required for the normal mitochondrial control of Pdr3. A protein of unknown function called Lgel was identified as a participant in $\rho^{0}$-induced gene expression (Zhang et al., 2005). Lge1 is involved in ubiquitination of histone H2B (Hwang et al., 2003) but this function seems to be distinct from its role in $\rho^{0}$ induction of PDR5 expression (Zhang et al., 2005). Mutants lacking Lge1 fail to fully induce PDR5 transcription in $\rho^{0}$ cells. Overproduction of an enzyme involved in biosynthesis of phosphatidylethanolamine (PE) was discovered to increase Pdr3-dependent transactivation

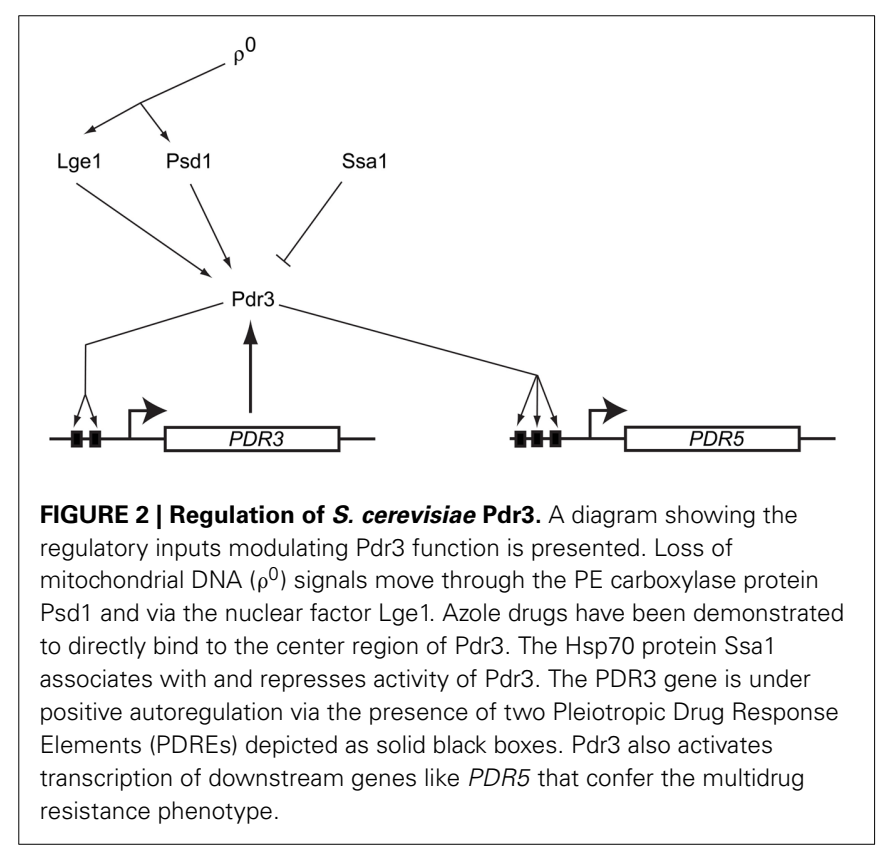


even in $\rho^{+}$cells (Gulshan et al., 2008). This enzyme, called Psd1, is one of two enzymes typically used to produce PE and is located in the inner membrane space of mitochondria (reviewed in Voelker, 1997). Surprisingly, overproduction of a catalytically-inactive form of Psd1 was still capable of inducing PDR5 expression even though this mutant enzyme could no longer carry out PE biosynthesis (Gulshan et al., 2008). The presence of Psd1 was required for normal $\rho^{0}$ signaling to occur consistent with this enzyme having a role in wild-type signal transduction.

Mass spectrometric analysis of purified Pdr3 led to the identification of the Hsp70 protein Ssal as a negative regulator of this transcription factor (Shahi et al., 2007). Overproduction of Ssal caused a decrease in Pdr3-dependent gene expression and hyperactive mutants exhibited less binding to Ssal in vivo than wild-type Pdr3. This reduction in Hsp70 association correlated with increased transcriptional activation capability is reminiscent of the regulation of steroid hormone receptors (Pratt and Toft, 1997); however, the presence of other heat shock proteins docked to Pdr3 has not been reported. Interestingly, both Pdr1 and Pdr3 have been reported to be induced by challenge with progesterone, furthering the analogy with a regulatory mechanism resembling steroid hormone receptors (Banerjee et al., 2008).

Further biochemical experiments seeking to identify interacting proteins capable of binding to the KIX domain of the transcriptional Mediator subunit Med15/Gal11 determined that both Pdr1 and Pdr3 interacted with this protein region (Thakur et al., 2008). The Mediator complex is composed of roughly 20 different proteins that act to provide a link between sequencespecific transcriptional regulatory proteins and the RNA polymerase II machinery (see Casamassimi and Napoli, 2007 for a review). Biochemical and genetic experiments have separated the Mediator complex into two different forms referred to as either S-Mediator (or core mediator) containing three and L-Mediator containing four subdomains (Poss et al., 2013). The three subdomains of S-Mediator are called Head, Middle, and Tail with Med15 contributing a component of the Tail complex of proteins (Beve et al., 2005). L-Mediator contains an additional subcomplex consisting of the cyclin-dependent kinase Cdk8 (or Med15/Srb8) and attendant cyclin: cyclinC (Srb11) (reviewed in Conaway and Conaway, 2011). Two other large proteins designated Med12 (Srb8) and Med13 (Srb9) complete the Cdk8 complex.

Interactions between Pdr3 (and Pdr1) and Med15 are crucial for normal levels of downstream gene expression under all conditions (Shahi et al., 2010). However, activation of Pdr3 function in $\rho^{0}$ cells still occurs in med15 $\Delta$ cells. Loss of the Med12 protein from the Cdk8 complex completely blocked $\rho^{0}$ induction of PDR5 transcription but had a negligible effect on expression in $\rho^{+}$cells. These findings argue that Med12 is a key target for activated transcription supported by Pdr3, at least in $\rho^{0}$ cells. Generally speaking, the Cdk8 complex is thought to serve repressive functions in terms of transcriptional control but more recent data argue that this complex also has positive influences on gene expression as illustrated by the case of Pdr3 activation in $\rho^{0}$ cells.

\section{MULTIDRUG RESISTANCE IN CANDIDA ALBICANS}

The major human fungal pathogen is the yeast Candida albicans. This organism, while susceptible to azole drug treatment, is readily detected to acquire a multidrug resistance phenotype that includes robust tolerance to this important class of antifungal drug (reviewed in Pfaller, 2012). Next to the current picture of S. cerevisiae multidrug resistance, the situation in C. albicans is the best understood and has been the focus of authoritative reviews (Cannon et al., 2009; Sanglard et al., 2009; Morschhauser, 2010). Here we will focus our attention on the transcriptional regulatory proteins implicated in clinically relevant resistance phenotypes.

\section{MEMBRANE PROTEINS IMPORTANT IN MULTIDRUG RESISTANCE IN $C$. ALBICANS}

The two best characterized genes involved in multidrug resistance in C. albicans are the $\mathrm{ABC}$ transporter-encoding CDR1 gene (Prasad et al., 1995) and the MFS protein-encoding MDR1 locus (Fling et al., 1991). Both of these resistance determinants are localized to the plasma membrane in C. albicans (Manoharlal et al., 2008; Basso et al., 2010; Kapoor et al., 2010). CDR1 was isolated on the basis of complementation of the drug hypersensitivity of a $p d r 5 \Delta$ mutant in S. cerevisiae. Loss of CDR1 led to a pronounced drug sensitive phenotype in C. albicans. A closely related $\mathrm{ABC}$ transporter-encoding gene, designated $C D R 2$, also contributes to drug resistance when overproduced or when $C D R 1$ is deleted (Sanglard et al., 1997).

MDR1 has been documented to be overexpressed in a number of different clinical isolates (Morschhauser, 2002); however, its loss does not appear to have significant effects on baseline drug resistance. The plasma membrane location of these transporter proteins supports the view that these proteins act as efflux pumps for a range of different drugs (Schuetzer-Muehlbauer et al., 2003; Lettner et al., 2010). Multidrug resistance in C. albicans is associated in large part with transcriptional induction of the genes encoding these membrane proteins.

\section{TAC1}

The first insight into the molecular basis of transcriptional regulation of multidrug resistance in $C$. albicans came from the identification of the TAC1 locus. As with PDR1 and PDR3 in S. cerevisiae, genetic observations drove the discovery of the TAC1 gene. Analyses of azole tolerant $C$. albicans isolates led to the discovery of loss of heterozygosity/aneuploidy around the mating type loci (MTL) gene cluster (Rustad et al., 2002). Using this observation as a starting point, Sanglard and colleagues took a candidate gene approach by disrupting several different $\mathrm{Zn}_{2} \mathrm{Cys}_{6}$ zinc cluster-encoding genes in this chromosomal region (Coste et al., 2004). Loss of one of these genes, designated TAC1 (Transcriptional Activator of Cdr genes), resulted in a strain displaying enhanced azole susceptibility and depressed expression of the CDR1 ABC transporter-encoding gene.

Along with a requirement for TAC1 to confer normal wild-type expression of CDR 1 and drug resistance, evidence was obtained that two different changes in the TAC1 gene influenced its function. First, a number of different substitution and even small deletion mutations strongly enhanced the function of Tac1 (Coste et al., 2007). Secondly, chromosomal rearrangements of chromosome 5 were detected that led to loss of heterozygosity and changes in the dosages of the linked ERG11 and TAC1 genes. These structural changes in chromosome 5 were found to lead to 
the amplification and likely overexpression of ERG11 and TAC1 (Coste et al., 2007; Selmecki et al., 2008). These findings are consistent with a model in which Tacl can be activated either by changes in its primary sequence or simply by overproducing the wild-type factor. Consistent with the notion that increased expression of Tacl leads to increased function comes from data that the TAC1 gene is positively autoregulated (Liu et al., 2007; Znaidi et al., 2007).

Although we do not yet know the nature of the signals that control Tac1, the currently available data suggest that its regulation may resemble that of $\mathrm{Pdr} 3$ in $S$. cerevisiae. Both of these factors can be activated by mutations along their respective primary sequence and the genes encoding these regulators are positively autoregulated.

\section{Mrr1}

A second zinc cluster-containing transcription factor that is an important contributor to drug resistance was identified in cells that were already known to overproduce MDR1 (Morschhauser et al., 2007). Transcriptional profiling experiments demonstrated that fluconazole resistant isolates shared a common overproduced transcript encoding a zinc cluster-containing transcription factor. This regulatory protein was designated Mrr1 (multidrug resistance regulator). The presence of Mrr1 is required for the observed overproduction of MDR1 in fluconazole resistant strains. While the MDR1 promoter contains binding sites for other positive regulators, loss of Mrr1 is sufficient to abrogate the overproduction that occurs in drug resistant isolates. This argues that Mrr1 is the key transcriptional regulator during development of drug resistance involving $M D R 1$ overproduction (Dunkel et al., 2008). Importantly, azole resistant clinical isolates have been described that overproduce $M D R 1$ and are dependent upon the presence of this MFS protein for this drug resistance (White, 1997; Wirsching et al., 2000).

Genetic activation of Mrrl shows similar behavior to other zinc cluster-containing transcription factors in which single amino acid substitutions lead to dramatic induction of Mrr1 transcriptional activity (Dunkel et al., 2008). Detailed analyses of the functional subdomains within Mrr1 indicate that the regulation of this factor is likely to be complex with separable inhibitory and activation domains (Schubert et al., 2011b). Chromatin immunoprecipitation experiments also indicated that Mrr1 is likely to control its own expression (Schubert et al., 2011a) as mentioned above for Tac1. Both these C. albicans factors appear to share common overall features with ScPdr3 that is also autoregulated and can be genetically activated by a range of different mutations (reviewed in Moye-Rowley, 2003b).

Along with their important effects on multidrug resistance and critically azole tolerance, these transcription factors have been examined for their influence on virulence. Systematic introduction of GOF forms of TAC1 and MRR1 indicated a fitness cost in a gastrointestinal colonization model caused by either mutant gene individually that was exacerbated with their combination (Sasse et al., 2012). These authors suggested an interesting potential rationale for the common observation that clinical isolates of azole resistant $C$. albicans contain either TAC1 or MRR1 mutations but not both. Although the double TAC1 MRR1 strains were robustly azole tolerant, the fitness cost could be so great as to exclude this genetic combination in vivo. More recent data suggests that certain combinations of azole resistance mechanisms, including simultaneous presence of mutations in TAC1 and MRR1, may be tolerated (Morio et al., 2013).

A different infection model was used to investigate similar mutations in these same transcription factor genes (tail vein injection) (Lohberger et al., 2014). Using this bloodstream infection model, no significant fitness defect was found consistent with the interpretation that, at least under certain conditions, GOF forms of these transcription factors could be well-tolerated in vivo.

\section{OTHER TRANSCRIPTION FACTORS INVOLVED IN DRUG RESISTANCE}

The intensive investigation of drug resistance in C. albicans has led to identification of a range of different transcriptional regulatory proteins that participate at some level in drug resistance including $\mathrm{Ndt} 80$ and $\mathrm{Mcm} 1$ among others. These factors in general have not been associated with clinically-relevant drug resistance and seem to play roles as expression modifiers of target genes involved in azole resistance (Mogavero et al., 2011; Sasse et al., 2011).

Two other transcription factors have been linked to certainly azole resistance if not multidrug resistance in $C$. albicans. The $\mathrm{Upc} 2$ transcriptional regulator is a positive modulator of sterol biosynthesis and mutations in this factor lead to pronounced azole resistance (Flowers et al., 2012). The effects of Upc2 on drug resistance occur via its role as a key regulator of sterol biosynthesis making this factor unlikely to serve as a true multidrug resistance determinant. CAP1 encodes the C. albicans ScYap1 homolog but does not appear to participate in drug resistance when expressed at normal levels. (Alarco et al., 1997; Alarco and Raymond, 1999). Cap1 clearly regulates MDR1 (Rognon et al., 2006) but this may have more to do with a role for Mdr1 in the oxidative stress response than drug resistance.

\section{MULTIDRUG RESISTANCE IN C. GLABRATA}

Candida glabrata is the second most common cause of bloodstream and mucosal candidiasis (10-30\%) in the United States, with a high mortality rate (38-53\%) (Richter et al., 2005; Pfaller and Diekema, 2007). C. glabrata is intrinsically resistant to fluconazole, a common azole drug that targets the fungal specific ergosterol biosynthetic pathway, with resistance known to further increase during drug therapy (8-27\% of isolates demonstrating a fluconazole MIC $\geq 64 \mu \mathrm{g} \mathrm{ml}^{-1}$ ) (Ostrosky-Zeichner et al., 2003; Pfaller et al., 2004). As for other fungi, C. glabrata azole resistance can be the result of an alteration of the target enzyme by either overexpression or mutations in its encoding gene, ERG11, that reduces the efficacy of the drug (Henry et al., 2000).

Another frequent basis for multiazole tolerance phenotype is enhanced drug efflux mediated by the activation of expression of ABC transporters like $C g C d r 1, C g C d r 2$ (Pdh1), and CgSnq2 (Sanglard et al., 1995, 1997; Miyazaki et al., 1998; Redding et al., 2003; Bennett et al., 2004; Vermitsky and Edlind, 2004; Sanguinetti et al., 2005; Torelli et al., 2008). CgCdr1 seems to be the chief $\mathrm{ABC}$ transporter that is constitutively upregulated in most of the drug resistant clinical isolates, either by itself, or as a combination with $C g C d r 2(P d h 1)$ and/or CgSnq2. Deletion of $C g C d r 1$ leads to increased intracellular azole accumulation and 
hypersensitivity to different azoles, both in clinical isolates as well as lab strains. The ABC transporters mentioned above are regulated by a $\mathrm{Zn}_{2} \mathrm{Cys}_{6}$ zinc cluster-containing transcription factor encoded by $C g P D R 1$. It is now well established that $C g P D R 1$ exhibits GOF mutations in most of the drug resistant clinical isolates of $C$. glabrata leading to upregulation of the transcription factor, which is responsible for high expression of the target genes that encode drug efflux pumps mediating multidrug resistance. It has been demonstrated that some of these CgPDR1 GOF mutations also lead to hypervirulence in a mouse model for systemic candidiasis (Ferrari et al., 2009). Interestingly, further work from this same group found that $\mathrm{CgPdr} 1$ regulated $\mathrm{ABC}$ transporter CgCdr1 and a mitochondrial protein, Pup1, is at least partially responsible for this gain of virulence (Ferrari et al., 2011b).

\section{CgPdr1}

Consistent with the fact that C. glabrata is phylogenetically closer to $S$. cerevisiae than C. albicans, the multidrug resistance pathways in S. cerevisiae and C. glabrata share more extensive similarities than with the cognate $C$. albicans system. The molecular players involved in drug resistance, $\rho^{0}$-induced PDR pathway activation, and the fact that the pivotal control of multidrug resistance in $C$. glabrata is at the transcriptional level are all shared with $S$. cerevisiae. However, there are interesting differences as well. Unlike S. cerevisiae, C. glabrata ABC transporters involved in multidrug resistance is regulated by the single transcription factor CgPdr1. CgPdr1 seems to be a blend of transcription factors ScPdr1 and ScPdr3 that modulate drug resistance in S. cerevisiae. Though CgPdr1 shares greater identity with ScPdr1 in terms of protein sequence, the C. glabrata transcription factor has binding elements in its own promoter contributing to its autoregulation, just as in the case of ScPdr3. Also like $\mathrm{ScPdr} 3, \mathrm{CgPdr} 1$ responds to Pdr pathway activation in $\rho^{0}$ cells that lack mitochondrial DNA, as well as when the mitochondrial enzyme phosphatidylserine decarboxylase (ScPsd1) is overproduced (Paul et al., 2011). The role played by the Mediator component Gall1 in regulation of CgPdr1 is also interestingly different in C. glabrata when compared to its cognate role in $S$. cerevisiae. There are 2 GAL11 paralogs (CgGAL11A and $C g G A L 11 B)$ in C. glabrata, of which only $C g G A L 11 A$ seems to be important for CgPdr1 induced drug resistance (Thakur et al., 2008). The requirement for CgGal11A is however seen only in $\rho^{+}$and not in $\rho^{0}$ cells, unlike in S. cerevisiae (Paul et al., 2011). Moreover, CgGal11A is required for induction of drug resistance upon azole challenge in $\rho^{+}$cells (Figure 3 ). This phenomenon of xenobiotic/drug-induced efflux pump activation, while not consistently seen in S. cerevisiae, is similar to that observed in C. albicans (Liu et al., 2005).

C. glabrata respiratory deficient mutants $\left(\rho^{0}\right)$ that have been generated in vitro by either ethidium bromide or azole treatment (where $\rho^{0}$ cells occur at high frequency), exhibit a growth defect phenotype and reduced virulence (Brun et al., 2005). However, these same cells also possess robust drug resistance that is primarily based on activation of the transcription factor CgPdr1 and upregulation of its target gene CgCdr1 (Vermitsky and Edlind, 2004; Tsai et al., 2006). Interestingly, such mutants have, albeit rarely, been recovered from patients undergoing fluconazole treatment, suggesting that this mechanism of drug resistance

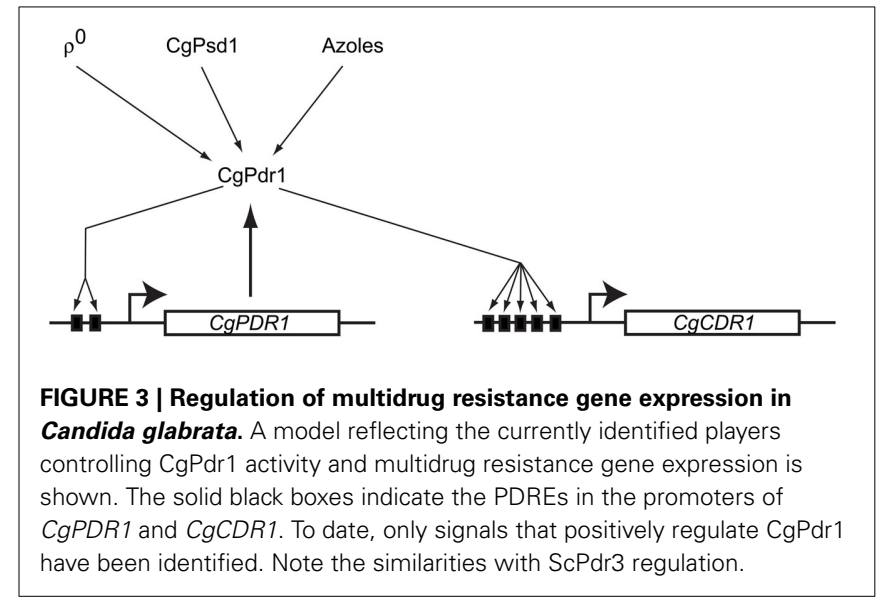

may be clinically relevant (Bouchara et al., 2000). Recently, it was reported that an azole resistant $C$. glabrata $\rho^{0}$ isolate from the clinic (containing a wild-type CgPDR1 gene) exhibited higher virulence and in vivo fitness in a murine infection model than its azole-susceptible and respiration-competent parental strain (Ferrari et al., 2011a).

Intrinsic low susceptibility and high frequency of resistance to widely used azole antifungals have led to greater use of other drugs, particularly amphotericin B and echinocandins in treatment of candidemias involving C. glabrata (Sanguinetti et al., 2005). Echinocandins such as caspofungin and micafungin are lipopeptide inhibitors of $\beta$-1,3-glucan synthase and interfere with fungal specific cell wall synthesis. This class of antifungals is active against most Candida species, including C. glabrata (OstroskyZeichner et al., 2003; Pfaller et al., 2008) and has been used as first-line therapy against C. glabrata infections (Pappas et al., 2009). Echinocandin resistance in C. glabrata is rare by comparison to azole tolerance but increasing in frequency in response to increasing clinical use (Pfaller et al., 2012). Echinocandin resistance maps to genes encoding components of the $\beta-1,3-$ glucan synthase (recently discussed in Alexander et al., 2013) and as such is considered outside the typical multidrug resistance determinants in this organism.

To overcome the intrinsic and high frequency acquisition of azole resistance in C. glabrata, alternative therapies have also been employed. As mentioned above, echinocandins are effective antifungal agents against $C$. glabrata but resistance to these drugs is on the rise. Combined therapies have also been explored but unexpected complications have arisen in some cases (Alves et al., 2012). An oral drug that represents an alternative to azoles is 5-flurocytosine (5-FC), although there are concerns regarding resistance and toxicity associated with high doses used to negate resistance. Surprisingly, 5-FC/azole combinations have been reported to have an antagonistic effect in C. glabrata (Te Dorsthorst et al., 2002; Alves et al., 2012). This antagonistic effect seems to be mediated through the Pdr pathway as it was found that this phenomenon was abrogated in Cgpdr1 $\Delta$ and $C g c d r 1 \Delta$ strains (Steier et al., 2013). 5-FC exposure resulted in 6-fold induction of $\mathrm{CgCdr} 1$ that was $\mathrm{CgPdr} 1$-dependent even though 5-FC is not a CgCdr1 substrate. Interestingly, 5-FC exposure induced high frequency formation of petite $\left(\rho^{0}\right)$ mutants 
that upregulate CgPdr1-dependent CgCdr1 activation. Though the molecular mechanism contributing to this antagonistic effect is not clearly understood, it seems that the mitochondrial retrograde signal that activate $\mathrm{CgPdr} 1$ is the likely basis for this phenomenon in C. glabrata.

\section{OTHER PATHWAYS OF MULTIDRUG RESISTANCE}

As mentioned previously for C. albicans, C. glabrata also contains a number of MFS-encoding genes. While function of these membrane transporter proteins remains to be characterized, a $C$. glabrata homolog of ScFlr1 has been investigated for its potential role as a multidrug resistance determinant (Chen et al., 2007). The C. glabrata homolog was designated CgFLR1 and as in both $C$. albicans and $S$. cerevisiae, disruption mutations lacking this gene did have drug phenotypes but were unaffected in terms of fluconazole susceptibility. CgFLR1 is regulated by the C. glabrata homolog of ScYap1 (CgAP1) but this regulation does not appear to be involved in normal azole tolerance. More recent experiments have demonstrated that additional MFS proteins contributed to multidrug resistance including CgTPO3 and CgQDR2 (Costa et al., 2013, 2014).

\section{MULTIDRUG RESISTANCE IN ASPERGILLUS FUMIGATUS}

Significant increases in immunocompromised population over the past few decades have resulted in a concomitant increase in invasive aspergillosis, with Aspergillus fumigatus being the most common causative agent (Denning et al., 2013a,b). Invasive aspergillosis is associated with a high rate of morbidity and mortality (as high as 50\%) in these patients (Nivoix et al., 2008). However, there are limited effective antifungal drugs available to treat invasive apergillosis (see Pound et al., 2011 for a review). Though amphotericin B has been used with some success, it has been associated with high nephrotoxicity. Echinocandins such as caspofungin have been effective only as a topical agent and has been at best fungistatic. The only oral and the most widespread treatment against invasive aspergillosis has been triazole drugs, particularly itraconazole and voriconazole. However, continuous use of triazoles has led to the development of resistance against different azole drugs used for therapy, with clinical instances of such drug resistance increasing significantly in the last decade.

A prevalent mechanism that is associated with multiazole resistance against $A$. fumigatus has been alterations in the levels of the target enzyme, $14 \alpha$-sterol demethylase, encoded by cyp $51 A$ gene (that also happens to have a paralog in A. fumigatus, namely cyp51B). The $\mathrm{L} 98 \mathrm{H}$ mutation in the cyp51A gene linked with a $34 \mathrm{bp}$ tandem repeat sequence in its promoter has been associated with a large number of multi-azole resistant $A$. fumigatus clinical isolates (Snelders et al., 2008). This mutation was first reported in the Netherlands (where use of azoles as fungicides in agriculture is common), and was later reported from different parts of the world, indicating the spread of this mutation (Lockhart et al., 2011; Camps et al., 2012a; Chowdhary et al., 2012). Other mutational hotspots in $c y p 51 \mathrm{~A}$ associated with drug resistant isolates have also been identified, though they have been less common and widespread (Recently reviewed in Lelievre et al., 2013).

Since 2008, a large proportion of multi-azole resistant $A$. fumigatus clinical isolates have been shown to be non-cyp51A dependent, implicating the role of other drug resistance mechanisms. A comprehensive study involving 64 azole resistant $A$. fumigatus strains done in the United Kingdom revealed that $43 \%$ of the cases had no cyp51A mutations associated with them (Bueid et al., 2010). Subsequent studies have identified that non-cyp51A based drug resistance is on the rise, with more than $50 \%$ of the cases involving alternate mechanisms (Camps et al., 2012b; Escribano et al., 2013). Analysis of these non-cyp51A based drug resistance isolates have revealed overexpression of $\mathrm{ABC}$ transporters in many of these cases, particularly that of $c d r 1 B(a b c B)$ (Fraczek et al., 2013).

Overexpression of efflux pumps is a common and well documented mechanism involved in the drug resistance of pathogenic yeasts such as $C$. albicans and C. glabrata as discussed above. They involve two types: the ABC class and the MFS class. The genes encoding these transporters [around $50 \mathrm{ABC}$ (Kovalchuk and Driessen, 2010) and nearly 300 MFS class] are highly redundant in A. fumigatus, and some of them have been implicated in multi-azole resistance in A. fumigatus in recent years (Slaven et al., 2002; Nascimento et al., 2003; Ferreira et al., 2005). Among the transporters so far characterized in drug resistant clinical isolates of $A$. fumigatus, $c d r 1 B(a b c B)$ levels has been found to be most consistently and prominently overexpressed, with $c d r 1 B$ mRNA transcript levels induced between 5-30 fold in these strains. Deletion of $c d r 1 B$ also resulted in a 4 -fold increase in susceptibility to itraconazole in both drug susceptible and resistant strains (Fraczek et al., 2013). In an independent study, the $a b c B$ gene was disrupted in three different $A$. fumigatus genetic backgrounds, resulting in susceptibility to different azoles tested: voriconazole, itraconazole as well as ketoconazole (Paul et al., 2013). Deletion of $a b c A$, another ABCG class transporter like $a b c B$, also resulted in drug sensitivity, at least in two different $A$. fumigatus genetic backgrounds, although to a lesser extent. Interestingly, overexpression of abcA led to an enhanced tolerance to azole drugs. This study also demonstrated that both $a b c A$ and $a b c B$ promoters are induced in the presence of drugs, just like in the case of $C g C D R 1$. The action of efflux pumps (AfuMDR4) has also been implicated in fungal resistance within the biofilm, especially in CF patients (Rajendran et al., 2011).

As of yet, we know very little of the identity of transcriptional regulatory proteins involved in control of multidrug resistance in A. fumigatus. Analysis of a truncated Afyap1 (A. fumigatus homolog of ScYap1) determined that this mutant protein led to antifungal drug resistance (as found for truncated ScYap1based drug resistance in yeasts), along with conferring tolerance to oxidative stress. However, multiple copies of full-length Afyap 1 exhibited voriconazole susceptibility comparable with that of a wild-type A. fumigatus strain (Qiao et al., 2010). Together, these data suggest that Afyap1, like the bZip cognate proteins in yeast, exerts effects on antifungal drug resistance only upon mutational activation.

\section{PROSPECTUS}

The limited repertoire of antifungal drugs makes developing new modalities an important and pressing need. However, a goal of crucial importance to the enterprise of antifungal therapies in particular and drug-based therapies in general is to understand 
mechanisms of drug resistance. Multidrug resistance is an especially serious issue as a small number (often one) of genetic changes can lead to loss of susceptibility to multiple drugs simultaneously. In terms of antifungal multidrug resistance, our most developed picture applies to the yeast Saccharomyces cerevisiae, due in large part to the facile genetics of this organism. In recent years, important progress has been made in the two major pathogenic Candida species, C. albicans and C. glabrata. While there are significant similarities between the Candida species and S. cerevisiae, important differences have been described. The increasing development and application of genetic technologies in the Candida species will expedite direct study of the resistance mechanisms in these organisms. This is crucial to ensure continued utility of existing and future antifungal drugs.

While we have a fairly extensive catalogue of genes that are likely participants in the process of multidrug resistance, our understanding of how these genes are regulated is still very incomplete. In some cases, the identities of the transcription factors that control the multidrug resistance genes are well-established; yet a detailed picture of how the activity of these factors is regulated is not available. This will be an important future goal as interference with regulation of multidrug resistance gene expression has promise as a potential avenue to prevent development of this phenotype.

Improvements in medical care in regards to longer term survival in the face of immunosuppression has led to a greater chronic reliance on antimicrobial chemotherapy. Candida bloodstream infections are now the 4th most common form of nosocomial infection seen (Lewis, 2009). The occurrence of aspergillosis is also on the rise and outcomes associated with azole tolerant forms of this filamental fungal pathogen are dramatically worsened compared to azole susceptible fungi (Van Der Linden et al., 2011). Continued progress in the molecular understanding of antifungal drug resistance is an crucial step toward ensuring the sustainability of antifungal drug therapy and confidently expecting to treat these microbial pathogens in the future.

\section{ACKNOWLEDGMENTS}

Our work on multidrug resistance has been supported by NIH grants GM49825 and AI92331.

\section{REFERENCES}

Alarco, A. M., Balan, I., Talibi, D., Mainville, N., and Raymond, M. (1997). AP-1-mediated multidrug resistance in Saccharomyces cerevisiae requires FLR1 encoding a transporter of the major facilitator superfamily. J. Biol. Chem. 272, 19304-19313. doi: 10.1074/jbc.272.31.19304

Alarco, A. M., and Raymond, M. (1999). The bZip transcription factor Caplp is involved in multidrug resistance and oxidative stress response in Candida albicans. J. Bacteriol. 181, 700-708.

Alexander, B. D., Johnson, M. D., Pfeiffer, C. D., Jimenez-Ortigosa, C., Catania, J., Booker, R., et al. (2013). Increasing echinocandin resistance in Candida glabrata: clinical failure correlates with presence of FKS mutations and elevated minimum inhibitory concentrations. Clin. Infect. Dis. 56, 1724-1732. doi: $10.1093 /$ cid/cit136

Alves, I. A., Bandeira, L. A., Mario, D. A., Denardi, L. B., Neves, L. V., Santurio, J. M., et al. (2012). Effects of antifungal agents alone and in combination against Candida glabrata strains susceptible or resistant to fluconazole. Mycopathologia 174, 215-221. doi: 10.1007/s11046-0129538-7
Ambudkar, S. V., Kimchi-Sarfaty, C., Sauna, Z. E., and Gottesman, M. M. (2003). P-glycoprotein: from genomics to mechanism. Oncogene 22, 7468-7485. doi: 10.1038/sj.onc. 1206948

Balzi, E., Chen, W., Ulaszewski, S., Capieaux, E., and Goffeau, A. (1987). The multidrug resistance gene PDR1 from Saccharomyces cerevisiae. J. Biol. Chem. 262, 16871-16879.

Balzi, E., and Goffeau, A. (1995). Yeast multidrug resistance: the PDR network. J. Bioenerget. Biomem. 27, 71-76. doi: 10.1007/BF02110333

Balzi, E., Wang, M., Leterme, S., Van Dyck, L., and Goffeau, A. (1994). PDR5: a novel yeast multidrug resistance transporter controlled by the transcription regulator PDR1. J. Biol. Chem. 269, 2206-2214.

Banerjee, D., Lelandais, G., Shukla, S., Mukhopadhyay, G., Jacq, C., Devaux, F., et al. (2008). Responses of pathogenic and nonpathogenic yeast species to steroids reveal the functioning and evolution of multidrug resistance transcriptional networks. Eukaryot. Cell 7, 68-77. doi: 10.1128/EC.00256-07

Basso, L. R. Jr., Gast, C. E., Mao, Y., and Wong, B. (2010). Fluconazole transport into Candida albicans secretory vesicles by the membrane proteins Cdr1p, Cdr2p, and Mdr1p. Eukaryot. Cell 9, 960-970. doi: 10.1128/EC.00355-09

Bauer, B. E., Wolfger, H., and Kuchler, K. (1999). Inventory and function of yeast $\mathrm{ABC}$ proteins: about sex, stress, pleiotropic drug and heavy metal resistance. Biochim. Biophys. Acta. 1461, 217-236. doi: 10.1016/S0005-2736(99)00160-1

Bennett, J. E., Izumikawa, K., and Marr, K. A. (2004). Mechanism of increased fluconazole resistance in Candida glabrata during prophylaxis. Antimicrob. Agents Chemother. 48, 1773-1777. doi: 10.1128/AAC.48.5.1773-1777.2004

Beve, J., Hu, G. Z., Myers, L. C., Balciunas, D., Werngren, O., Hultenby, K., et al. (2005). The structural and functional role of Med5 in the yeast Mediator tail module. J. Biol. Chem. 280, 41366-41372. doi: 10.1074/jbc.M511181200

Bissinger, P. H., and Kuchler, K. (1994). Molecular cloning and expression of the $S$. cerevisiae STS1 gene product. J. Biol. Chem. 269, 4180-4186.

Bosis, E., Salomon, D., Ohayon, O., Sivan, G., Bar-Nun, S., and Rabinovich, E. (2010). Ssz1 restores endoplasmic reticulum-associated protein degradation in cells expressing defective cdc48-ufd1-npl4 complex by upregulating cdc48. Genetics 184, 695-706. doi: 10.1534/genetics.109.111419

Bossier, P., Fernandes, L., Rocha, D., and Rodrigues-Pousada, C. (1993). Overexpression of YAP2, coding for a new yAP protein, and YAP1 in S. cerevisiae alleviates growth inhibition caused by 1,10-phenanthroline. J. Biol. Chem. 268, 23640-23645.

Bouchara, J. P., Zouhair, R., Le Boudouil, S., Renier, G., Filmon, R., Chabasse, D., et al. (2000). In-vivo selection of an azole-resistant petite mutant of Candida glabrata. J. Med. Microbiol. 49, 977-984.

Brown, G. D., Denning, D. W., and Levitz, S. M. (2012). Tackling human fungal infections. Science 336, 647. doi: 10.1126/science.1222236

Brun, S., Dalle, F., Saulnier, P., Renier, G., Bonnin, A., Chabasse, D., et al. (2005). Biological consequences of petite mutations in Candida glabrata. J. Antimicrob. Chemother. 56, 307-314. doi: 10.1093/jac/dki200

Bueid, A., Howard, S. J., Moore, C. B., Richardson, M. D., Harrison, E., Bowyer, P., et al. (2010). Azole antifungal resistance in Aspergillus fumigatus: 2008 and 2009. J. Antimicrob. Chemother. 65, 2116-2118. doi: 10.1093/jac/dkq279

Camps, S. M., Rijs, A. J., Klaassen, C. H., Meis, J. F., O’Gorman, C. M., Dyer, P. S., et al. (2012a). Molecular epidemiology of Aspergillus fumigatus isolates harboring the TR34/L98H azole resistance mechanism. J. Clin. Microbiol. 50, 2674-2680. doi: 10.1128/JCM.00335-12

Camps, S. M., Van Der Linden, J. W., Li, Y., Kuijper, E. J., Van Dissel, J. T., Verweij, P. E., et al. (2012b). Rapid induction of multiple resistance mechanisms in Aspergillus fumigatus during azole therapy: a case study and review of the literature. Antimicrob. Agents Chemother. 56, 10-16. doi: 10.1128/AAC.05088-11

Cannon, R. D., Lamping, E., Holmes, A. R., Niimi, K., Baret, P. V., Keniya, M. V., et al. (2009). Efflux-mediated antifungal drug resistance. Clin. Microbiol. Rev. 22, 291-321, doi: 10.1128/CMR.00051-08

Carvajal, E., Van Den Hazel, H. B., Cybularz-Kolaczkowska, A., Balzi, E., and Goffeau, A. (1997). Molecular and phenotypic characterization of yeast PDR1 mutants that show hyperactive transcription of various $\mathrm{ABC}$ multidrug transporter genes. Mol. Gen. Genet. 256, 406-415. doi: 10.1007/s004380 050584

Casamassimi, A., and Napoli, C. (2007). Mediator complexes and eukaryotic transcription regulation: an overview. Biochemie. 89, 1439-1446. doi: 10.1016/j.biochi.2007.08.002

Chen, K. H., Miyazaki, T., Tsai, H. F., and Bennett, J. E. (2007). The bZip transcription factor Cgap1p is involved in multidrug resistance and required for 
activation of multidrug transporter gene CgFLR1 in Candida glabrata. Gene 386, 63-72. doi: 10.1016/j.gene.2006.08.010

Chowdhary, A., Kathuria, S., Xu, J., Sharma, C., Sundar, G., Singh, P. K., et al. (2012). Clonal expansion and emergence of environmental multipletriazole-resistant Aspergillus fumigatus strains carrying the TR(3)(4)/L98H mutations in the cyp51A gene in India. PLoS ONE 7:e52871. doi: 10.1371/journal.pone.0052871

Coleman, S. T., Epping, E. A., Steggerda, S. M., and Moye-Rowley, W. S. (1999). Yap1p activates gene transcription in an oxidant-specific fashion. Mol. Cell. Biol. 19, 8302-8313.

Coleman, S. T., Tseng, E., and Moye-Rowley, W. S. (1997). Saccharomyces cerevisiae basic region-leucine zipper protein regulatory networks converge at the ATR1 structural gene. J. Biol. Chem. 272, 23224-23230. doi: 10.1074/jbc.272.37.23224

Conaway, R. C., and Conaway, J. W. (2011). Function and regulation of the Mediator complex. Curr. Opin. Genet. Dev. 21, 225-230. doi: 10.1016/j.gde.2011.01.013

Costa, C., Nunes, J., Henriques, A., Mira, N. P., Nakayama, H., Chibana, H., et al. (2014). Candida glabrata drug:H+ antiporter CgTpo3 (ORF CAGL0I10384g): role in azole drug resistance and polyamine homeostasis. J. Antimicrob. Chemother. doi: 10.1093/jac/dku044

Costa, C., Pires, C., Cabrito, T. R., Renaudin, A., Ohno, M., Chibana, H., et al. (2013). Candida glabrata drug:H+ antiporter CgQdr2 confers imidazole drug resistance, being activated by transcription factor CgPdr1. Antimicrob. Agents Chemother. 57, 3159-3167. doi: 10.1128/AAC.00811-12

Coste, A., Selmecki, A., Forche, A., Diogo, D., Bougnoux, M. E., D'Enfert, C., et al. (2007). Genotypic evolution of azole resistance mechanisms in sequential Candida albicans isolates. Eukaryot. Cell 6, 1889-1904. doi: 10.1128/EC.00 151-07

Coste, A. T., Karababa, M., Ischer, F., Bille, J., and Sanglard, D. (2004). TAC1, transcriptional activator of CDR genes, is a new transcription factor involved in the regulation of Candida albicans $\mathrm{ABC}$ transporters CDR1 and CDR2. Eukaryot. Cell 3, 1639-1652. doi: 10.1128/EC.3.6.1639-1652.2004

Cui, Z., Shiraki, T., Hirata, D., and Miyakawa, T. (1998). Yeast gene YRR1, which is required for resistance to 4-nitroquinoline- $\mathrm{N}$-oxide, mediates transcriptional activation of the multidrug resistance transporter gene SNQ2. Mol. Microbiol. 29, 1307-1315. doi: 10.1046/j.1365-2958.1998.01027.x

Decottignies, A., Kolaczkowski, M., Balzi, E., and Goffeau, A. (1994). Solubilization and charcterization of the overexpressed PDR5 multidrug resistance nucleotide triphophatase of yeast. J. Biol. Chem. 269, 12797-12803.

Delahodde, A., Delaveau, T., and Jacq, C. (1995). Positive autoregulation of the yeast transcription factor Pdr3p, involved in the control of the drug resistance phenomenon. Mol. Cell. Biol. 15, 4043-4051.

Delaunay, A., Isnard, A. D., and Toledano, M. B. (2000). H2O2 sensing through oxidation of the Yap1 transcription factor. EMBO J. 19, 5157-5166. doi: 10.1093/emboj/19.19.5157

Delaunay, A., Pflieger, D., Barrault, M. B., Vinh, J., and Toledano, M. B. (2002). A thiol peroxidase is an $\mathrm{H} 2 \mathrm{O} 2$ receptor and redox-transducer in gene activation. Cell 111, 471-481. doi: 10.1016/S0092-8674(02)01048-6

Delaveau, T., Delahodde, A., Carvajal, E., Subik, J., and Jacq, C. (1994). PDR3, a new yeast regulatory gene, is homologous to PDR1 and controls the multidrug resistance phenomenon. Mol. Gen. Genet. 244, 501-511. doi: 10.1007/BF00583901

Denning, D. W., Pleuvry, A., and Cole, D. C. (2013a). Global burden of allergic bronchopulmonary aspergillosis with asthma and its complication chronic pulmonary aspergillosis in adults. Med. Mycol. 51, 361-370. doi: 10.3109/13693786.2012.738312

Denning, D. W., Pleuvry, A., and Cole, D. C. (2013b). Global burden of chronic pulmonary aspergillosis complicating sarcoidosis. Eur. Respir. J. 41, 621-626. doi: 10.1183/09031936.00226911

Derisi, J., Van Den Hazel, B., Marc, P., Balzi, E., Brown, P., Jacq, C., et al. (2000). Genome microarray analysis of transcriptional activation in multidrug resistance yeast mutants. FEBS Lett. 470, 156-160. doi: 10.1016/S00145793(00)01294-1

Devaux, F., Carvajal, E., Moye-Rowley, S., and Jacq, C. (2002). Genome-wide studies on the nuclear PDR3-controlled response to mitochondrial dysfunction in yeast. FEBS Lett. 515, 25-28. doi: 10.1016/S0014-5793(02)02387-6

Devaux, F., Marc, P., Bouchoux, C., Delaveau, T., Hikkel, I., Potier, M. C., et al. (2001). An artificial transcription activator mimics the genome-wide properties of the yeast Pdr1 transcription factor. EMBO Rep. 2, 493-498. doi: 10.1093/embo-reports/kve114
Dexter, D., Moye-Rowley, W. S., Wu, A.-L., and Golin, J. (1994). Mutations in the yeast PDR3, PDR4, PDR7 and PDR9 pleiotropic drug resistance loci affect the transcript level of an ATP binding cassette transporter encoding gene, PDR5. Genetics 136, 505-515.

Ducett, J. K., Peterson, F. C., Hoover, L. A., Prunuske, A. J., Volkman, B. F., and Craig, E. A. (2013). Unfolding of the C-terminal domain of the J-protein Zuol releases autoinhibition and activates Pdr1-dependent transcription. J. Mol. Biol. 425, 19-31. doi: 10.1016/j.jmb.2012.09.020

Dunkel, N., Blass, J., Rogers, P. D., and Morschhauser, J. (2008). Mutations in the multi-drug resistance regulator MRR1, followed by loss of heterozygosity, are the main cause of MDR1 overexpression in fluconazole-resistant Candida albicans strains. Mol. Microbiol. 69, 827-840. doi: 10.1111/j.13652958.2008.06309.x

Eisenman, H. C., and Craig, E. A. (2004). Activation of pleiotropic drug resistance by the J-protein and Hsp70-related proteins, Zuol and Ssz1. Mol. Microbiol. 53, 335-344. doi: 10.1111/j.1365-2958.2004.04134.x

Escribano, P., Pelaez, T., Munoz, P., Bouza, E., and Guinea, J. (2013). Is azole resistance in Aspergillus fumigatus a problem in Spain? Antimicrob. Agents Chemother. 57, 2815-2820. doi: 10.1128/AAC.02487-12

Fernandes, L., Rorigues-Pousada, C., and Struhl, K. (1997). Yap, a novel family of eight bZIP proteins in Saccharomyces cerevisiae with distinct biological functions. Mol. Cell. Biol. 17, 6982-6993.

Ferrari, S., Ischer, F., Calabrese, D., Posteraro, B., Sanguinetti, M., Fadda, G., et al. (2009). Gain of function mutations in CgPDR1 of Candida glabrata not only mediate antifungal resistance but also enhance virulence. PLoS Pathog. 5:e1000268. doi: 10.1371/journal.ppat. 1000268

Ferrari, S., Sanguinetti, M., De Bernardis, F., Torelli, R., Posteraro, B., Vandeputte, P., et al. (2011a). Loss of mitochondrial functions associated with azole resistance in Candida glabrata results in enhanced virulence in mice. Antimicrob. Agents Chemother. 55, 1852-1860. doi: 10.1128/AAC.01271-10

Ferrari, S., Sanguinetti, M., Torelli, R., Posteraro, B., and Sanglard, D. (2011b). Contribution of CgPDR1-regulated genes in enhanced virulence of azole-resistant Candida glabrata. PLoS ONE 6:e17589. doi: 10.1371/journal.pone.0017589

Ferreira, M. E., Colombo, A. L., Paulsen, I., Ren, Q., Wortman, J., Huang, J., et al. (2005). The ergosterol biosynthesis pathway, transporter genes, and azole resistance in Aspergillus fumigatus. Med. Mycol. 43(Suppl. 1), S313-S319. doi: $10.1080 / 13693780400029114$

Fling, M. E., Kopf, J., Tamarkin, A., Gorman, J. A., Smith, H. A., and Koltin, Y. (1991). Analysis of a Candida albicans gene that encodes a novel mechanism for resistance to benomyl and methotrexate. Mol. Gen. Genet. 227, 318-329. doi: 10.1007/BF00259685

Flowers, S. A., Barker, K. S., Berkow, E. L., Toner, G., Chadwick, S. G., Gygax, S. E., et al. (2012). Gain-of-function mutations in UPC2 are a frequent cause of ERG11 upregulation in azole-resistant clinical isolates of Candida albicans. Eukaryot. Cell 11, 1289-1299. doi: 10.1128/EC.00215-12

Fraczek, M. G., Bromley, M., Buied, A., Moore, C. B., Rajendran, R., Rautemaa, R., et al. (2013). The cdr1B efflux transporter is associated with noncyp51a-mediated itraconazole resistance in Aspergillus fumigatus. J. Antimicrob. Chemother. doi: 10.1093/jac/dkt075

Furuchi, T., Ishikawa, H., Miura, N., Ishizuka, M., Kajiya, K., Kuge, S., et al. (2001). Two nuclear proteins, Cin5 and Ydr259c, confer resistance to cisplatin in Saccharomyces cerevisiae. Mol. Pharmacol. 59, 470-474.

Gautschi, M., Lilie, H., Funfschilling, U., Mun, A., Ross, S., Lithgow, T., et al. (2001). RAC, a stable ribosome-associated complex in yeast formed by the DNaK-DnaJ homologs Sszlp and zuotin. Proc. Natl. Acad. Sci. U.S.A. 98, 3762-3767. doi: 10.1073/pnas.071057198

Gottesman, M. M., Hrycyna, C. A., Schoenlein, P. V., Germann, U. A., and Pastan, I. (1995). Genetic analysis of the multidrug transporter. Annu. Rev. Genet. 29, 607-649. doi: 10.1146/annurev.ge.29.120195.003135

Gulshan, K., and Moye-Rowley, W. S. (2007). Multidrug resistance in fungi. Eukaryot. Cell 6, 1933-1942. doi: 10.1128/EC.00254-07

Gulshan, K., Schmidt, J., Shahi, P., and Moye-Rowley, W. S. (2008). Evidence for the bifunctional nature of mitochondrial phosphatidylserine decarboxylase: role in Pdr3-dependent retrograde regulation of PDR5 expression. Mol. Cell. Biol. 28, 5851-5864. doi: 10.1128/MCB.00405-08

Hallstrom, T. C., Katzmann, D. J., Torres, R. J., Sharp, W. J., and Moye-Rowley, W. S. (1998). Regulation of transcription factor Pdr1p function by a Hsp70 protein in Saccharomyces cerevisiae. Mol. Cell. Biol. 18, 1147-1155. 
Hallstrom, T. C., Lambert, L., Schorling, S., Balzi, E., Goffeau, A., and MoyeRowley, W. S. (2001). Coordinate control of sphingolipid biosynthesis and multidrug resistance in Saccharomyces cerevisiae. J. Biol. Chem. 276, 23674-23680. doi: 10.1074/jbc.M101568200

Hallstrom, T. C., and Moye-Rowley, W. S. (2000a). Hyperactive forms of the Pdrlp transcription factor fail to respond to positive regulation by the Hsp70 protein Pdr13p. Mol. Microbiol. 36, 402-413. doi: 10.1046/j.1365-2958.2000.01858.x

Hallstrom, T. C., and Moye-Rowley, W. S. (2000b). Multiple signals from dysfunctional mitochondria activate the pleiotropic drug resistance pathway in Saccharomyces cerevisae. J. Biol. Chem. 275, 37347-37356. doi: 10.1074/jbc.M007338200

Henry, K. W., Nickels, J. T., and Edlind, T. D. (2000). Upregulation of ERG genes in Candida species by azoles and other sterol biosynthesis inhibitors. Antimicrob. Agents Chemother. 44, 2693-2700. doi: 10.1128/AAC.44.10.2693-2700.2000

Hikkel, I., Lucau-Danila, A., Delaveau, T., Marc, P., Devaux, F., and Jacq, C. (2003). A general strategy to uncover transcription factor properties identifies a new regulator of drug resistance in yeast. J. Biol. Chem. 278, 11427-11432. doi: 10.1074/jbc.M208549200

Hirata, D., Yano, K., Miyahara, K., and Miyakawa, T. (1994a). Saccharomyces cerevisiae YDR1, which encodes a member of the ATP-binding cassette (ABC) superfamily, is required for multidrug resistance. Curr. Genet. 26, 285-294. doi: 10.1007/BF00310491

Hirata, D., Yano, K., and Miyakawa, T. (1994b). Stress-induced transcriptional activation mediated by YAP1 and YAP2 genes that encode the Jun family of transcriptional activators in Saccharomyces cerevisiae. Mol. Gen. Genet. 242, 250-256. doi: 10.1007/BF00280413

Holohan, C., Van Schaeybroeck, S., Longley, D. B., and Johnston, P. G. (2013). Cancer drug resistance: an evolving paradigm. Nat. Rev. Cancer 13, 714-726. doi: 10.1038/nrc3599

Hussain, M., and Lenard, J. (1991). Characterization of PDR4, a Saccharomyces cerevisiae gene that confers pleiotropic drug resistance in high-copy number. Gene 101, 149-152. doi: 10.1016/0378-1119(91)90238-7

Hwang, W. W., Venkatasubrahmanyam, S., Ianculescu, A. G., Tong, A., Boone, C., and Madhani, H. D. (2003). A conserved RING finger protein required for histone H2B monoubiquitination and cell size control. Mol. Cell 11, 261-266. doi: 10.1016/S1097-2765(02)00826-2

Johnston, M. (1987). A model fungal gene regulatory mechanism: the GAL genes of Saccharomyces cerevisiae. Microbiol. Rev. 51, 458-476.

Kapoor, K., Rehan, M., Lynn, A. M., and Prasad, R. (2010). Employing information theoretic measures and mutagenesis to identify residues critical for drug-proton antiport function in Mdrlp of Candida albicans. PLoS ONE 5:e11041. doi: 10.1371/journal.pone.0011041

Katzmann, D. J., Burnett, P. E., Golin, J., Mahe, Y., and Moye-Rowley, W. S. (1994). Transcriptional control of the yeast PDR5 gene by the PDR3 gene product. Mol. Cell. Biol. 14, 4653-4661.

Katzmann, D. J., Hallstrom, T. C., Mahe, Y., and Moye-Rowley, W. S. (1996). Multiple Pdr1p/Pdr3p binding sites are essential for normal expression of the ATP binding cassette transporter protein-encoding gene PDR5. J. Biol. Chem. 271, 23049-23054. doi: 10.1074/jbc.271.38.23049

Katzmann, D. J., Hallstrom, T. C., Voet, M., Wysock, W., Golin, J., Volckaert, G., et al. (1995). Expression of an ATP-binding cassette transporter encoding gene (YOR1) is required for oligomycin resistance in Saccharomyces cerevisiae. Mol. Cell. Biol. 15, 6875-6883.

Keeven, J., Ko, D., Shallom, J., Uccellini, B., and Golin, J. (2002). PDR2 gainof-function mutations eliminate the need for Pdr1 and require the UBP6 product for resistance to translational inhibitors. Curr. Genet. 41, 11-19. doi: 10.1007/s00294-002-0274-2

Kihara, A., and Igarashi, Y. (2004). Cross talk between sphingolipids and glycerophospholipids in the establishment of plasma membrane asymmetry. Mol. Biol. Cell 15, 4949-4959. doi: 10.1091/mbc.E04-06-0458

Kolaczkowska, A., Manente, M., Kolaczkowski, M., Laba, J., Ghislain, M., and Wawrzycka, D. (2012). The regulatory inputs controlling pleiotropic drug resistance and hypoxic response in yeast converge at the promoter of the aminocholesterol resistance gene RTA1. FEMS Yeast Res. 12, 279-292. doi: 10.1111/j.1567-1364.2011.00768.x

Kolaczkowski, M., Kolaczkowska, A., Gaigg, B., Schneiter, R., and Moye-Rowley, W. S. (2004). Differential regulation of ceramide synthase components LAC1 and LAG1 in Saccharomyces cerevisiae. Eukaryot. Cell 3, 880-892. doi: 10.1128/EC.3.4.880-892.2004
Kovalchuk, A., and Driessen, A. J. (2010). Phylogenetic analysis of fungal ABC transporters. BMC Genomics 11:177. doi: 10.1186/1471-2164-11-177

Kristan, K., and Rizner, T. L. (2012). Steroid-transforming enzymes in fungi. J. Steroid Biochem. Mol. Biol. 129, 79-91. doi: 10.1016/j.jsbmb.2011.08.012

Kuge, S., and Jones, N. (1994). YAP1-dependent activation of TRX2 is essential for the response of $S$. cerevisiae to oxidative stress by hydroperoxides. EMBO J. 13, 655-664.

Kuge, S., Jones, N., and Nomoto, A. (1997). Regulation of yAP-1 nuclear localization in response to oxidative stress. EMBO J. 16, 1710-1720. doi: 10.1093/emboj/16.7.1710

Le Crom, S., Devaux, F., Marc, P., Zhang, X., Moye-Rowley, W. S., and Jacq, C. (2002). New insights into the pleiotropic drug resistance network from genomewide characterization of the YRR1 transcription factor regulation system. Mol. Cell. Biol. 22, 2642-2649. doi: 10.1128/MCB.22.8.2642-2649.2002

Lelievre, L., Groh, M., Angebault, C., Maherault, A. C., Didier, E., and Bougnoux, M. E. (2013). Azole resistant Aspergillus fumigatus: an emerging problem. Med. Mal. Infect. 43, 139-145. doi: 10.1016/j.medmal.2013.02.010

Leppert, G., Mcdevitt, R., Falco, S. C., Van Dyk, T. K., Ficke, M. B., and Golin, J. (1990). Cloning by gene amplification of two loci conferring multiple drug resistance in Saccharomyces. Genetics 125, 13-20.

Lettner, T., Zeidler, U., Gimona, M., Hauser, M., Breitenbach, M., and Bito, A. (2010). Candida albicans AGE3, the ortholog of the S. cerevisiae ARF-GAPencoding gene GCS1, is required for hyphal growth and drug resistance. PLoS ONE 5:e11993. doi: 10.1371/journal.pone.0011993

Lewis, R. E. (2009). Overview of the changing epidemiology of candidemia. Curr. Med. Res. Opin. 25, 1732-1740. doi: 10.1185/03007990902990817

Liu, T. T., Lee, R. E., Barker, K. S., Lee, R. E., Wei, L., Homayouni, R., et al. (2005). Genome-wide expression profiling of the response to azole, polyene, echinocandin, and pyrimidine antifungal agents in Candida albicans. Antimicrob. Agents Chemother. 49, 2226-2236. doi: 10.1128/AAC.49.6.2226-2236.2005

Liu, T. T., Znaidi, S., Barker, K. S., Xu, L., Homayouni, R., Saidane, S., et al. (2007). Genome-wide expression and location analyses of the Candida albicans Taclp regulon. Eukaryot. Cell 6, 2122-2138. doi: 10.1128/EC.00327-07

Lockhart, S. R., Frade, J. P., Etienne, K. A., Pfaller, M. A., Diekema, D. J., and Balajee, S. A. (2011). Azole resistance in Aspergillus fumigatus isolates from the ARTEMIS global surveillance study is primarily due to the TR/L98H mutation in the cyp51A gene. Antimicrob. Agents Chemother. 55, 4465-4468. doi: 10.1128/AAC.00185-11

Lohberger, A., Coste, A. T., and Sanglard, D. (2014). Distinct roles of Candida albicans drug resistance transcription factors TAC1, MRR1, and UPC2 in virulence. Eukaryot. Cell 13, 127-142. doi: 10.1128/EC.00245-13

Lucau-Danila, A., Delaveau, T., Lelandais, G., Devaux, F., and Jacq, C. (2003). Competitive promoter occupancy by two yeast paralogous transcription factors controlling the multidrug resistance phenomenon. J. Biol. Chem. 278, 52641-52650. doi: 10.1074/jbc.M309580200

Mahe, Y., Parle-Mcdermott, A., Nourani, A., Delahodde, A., Lamprecht, A., and Kuchler, K. (1996). The ATP-binding cassette multidrug transporter Snq2 of Saccharomyces cerevisiae: a novel target for the transcription factors Pdr1 and Pdr3. Mol. Microbiol. 20, 109-117. doi: 10.1111/j.1365-2958.1996.tb02493.x

Manoharlal, R., Gaur, N. A., Panwar, S. L., Morschhauser, J., and Prasad, R. (2008). Transcriptional activation and increased mRNA stability contribute to overexpression of CDR1 in azole-resistant Candida albicans. Antimicrob. Agents Chemother. 52, 1481-1492. doi: 10.1128/AAC.01106-07

Meyers, S., Schauer, W., Balzi, E., Wagner, M., Goffeau, A., and Golin, J. (1992). Interaction of the yeast pleiotropic drug resistance genes PDR1 and PDR5. Curr. Genet. 21, 431-436. doi: 10.1007/BF00351651

Michimoto, T., Aoki, T., Toh-E, A., and Kikuchi, Y. (2000). Yeast Pdr13p and Zuolp molecular chaperones are new functional Hsp70 and Hsp40 partners. Gene 257, 131-137. doi: 10.1016/S0378-1119(00)00381-4

Miyazaki, H., Miyazaki, Y., Geber, A., Parkinson, T., Hitchcock, C., Falconer, D. J., et al. (1998). Fluconazole resistance associated with drug efflux and increased transcription of a drug transporter gene, $P D H 1$, in Candida glabrata. Antimicrob. Agents Chemother. 42, 1695-1701.

Moen, M. D., Lyseng-Williamson, K. A., and Scott, L. J. (2009). Liposomal amphotericin B: a review of its use as empirical therapy in febrile neutropenia and in the treatment of invasive fungal infections. Drugs 69, 361-392. doi: 10.2165/00003495-200969030-00010

Mogavero, S., Tavanti, A., Senesi, S., Rogers, P. D., and Morschhauser, J. (2011). Differential requirement of the transcription factor $\mathrm{Mcml}$ for activation of 
the Candida albicans multidrug efflux pump MDR1 by its regulators Mrr1 and Cap1. Antimicrob. Agents Chemother. 55, 2061-2066. doi: 10.1128/AAC. 01467-10

Morio, F., Pagniez, F., Besse, M., Gay-Andrieu, F., Miegeville, M., and Le Pape, P. (2013). Deciphering azole resistance mechanisms with a focus on transcription factor-encoding genes TAC1, MRR1 and UPC2 in a set of fluconazole-resistant clinical isolates of Candida albicans. Int. J. Antimicrob. Agents 42, 410-415. doi: 10.1016/j.ijantimicag.2013.07.013

Morschhauser, J. (2002). The genetic basis of fluconazole resistance development in Candida albicans. Biochim. Biophys. Acta 1587, 240-248. doi: 10.1016/S09254439(02)00087-X

Morschhauser, J. (2010). Regulation of multidrug resistance in pathogenic fungi. Fungal Genet. Biol. 47, 94-106. doi: 10.1016/j.fgb.2009.08.002

Morschhauser, J., Barker, K. S., Liu, T. T., Blab-Warmuth, J., Homayouni, R., and Rogers, P. D. (2007). The transcription factor Mrrlp controls expression of the MDR1 efflux pump and mediates multidrug resistance in Candida albicans. PLoS Pathog. 3:e164. doi: 10.1371/journal.ppat.0030164

Moye-Rowley, W. S. (2003a). Regulation of the transcriptional response to oxidative stress in fungi: similarities and differences. Eukaryot. Cell 2, 381-389. doi: 10.1128/EC.2.3.381-389.2003

Moye-Rowley, W. S. (2003b). Transcriptional control of multidrug resistance in the yeast Saccharomyces. Prog. Nucleic Acids Res. Mol. Biol. 73, 251-279. doi: 10.1016/S0079-6603(03)01008-0

Nascimento, A. M., Goldman, G. H., Park, S., Marras, S. A., Delmas, G., Oza, U., et al. (2003). Multiple resistance mechanisms among Aspergillus fumigatus mutants with high-level resistance to itraconazole. Antimicrob. Agents Chemother. 47, 1719-1726. doi: 10.1128/AAC.47.5.1719-1726.2003

Nivoix, Y., Velten, M., Letscher-Bru, V., Moghaddam, A., Natarajan-Ame, S., Fohrer, C., et al. (2008). Factors associated with overall and attributable mortality in invasive aspergillosis. Clin. Infect. Dis. 47, 1176-1184. doi: 10.1086/592255

Nourani, A., Papajova, D., Delahodde, A., Jacq, C., and Subik, J. (1997). Clustered amino acid substitutions in the yeast transcription regulator Pdr3p increase pleiotropic drug resistance and identify a new central regulatory domain. $\mathrm{Mol}$. Gen. Genet. 256, 397-405. doi: 10.1007/s004380050583

Ostrosky-Zeichner, L., Rex, J., Pappas, P., Hamill, R. J., Larsen, R. A., Horowitz, H. W., et al. (2003). Antifungal susceptibility survey of 2,000 bloodstream Candida Antimicrob Agents Chemother 47, 3149-3154. doi: 10.1128/AAC.47.10.31493154.2003

Owsianik, G., Balzi, E., and Ghislain, M. (2002). Control of $26 \mathrm{~S}$ proteasome expression by transcription factors regulating multidrug resistance in Saccharomyces cerevisiae. Mol. Microbiol. 43, 1295-1308. doi: 10.1046/j.13652958.2002.02823.x

Panwar, S. L., and Moye-Rowley, W. S. (2006). Long chain base tolerance in Saccharomyces cerevisiae is induced by retrograde signals from the mitochondria. J. Biol. Chem. 281, 6376-6384. doi: 10.1074/jbc.M512115200

Pappas, P. G., Kauffman, C. A., Andes, D., Benjamin, D. K. Jr., Calandra, T. F., Edwards, J. E., et al. (2009). Clinical practice guidelines for the management of candidiasis: 2009 update by the Infectious Diseases Society of America. Clin. Infect. Dis. 48, 503-535. doi: 10.1086/596757

Paul, S., Diekema, D., and Moye-Rowley, W. S. (2013). Contributions of Aspergillus fumigatus ATP-binding cassette transporter proteins to drug resistance and virulence. Eukaryot. Cell 12, 1619-1628. doi: 10.1128/EC.00171-13

Paul, S., Schmidt, J. A., and Moye-Rowley, W. S. (2011). Regulation of the CgPdr1 transcription factor from the pathogen Candida glabrata. Eukaryot. Cell 10, 187-197. doi: 10.1128/EC.00277-10

Pfaller, M. A. (2012). Antifungal drug resistance: mechanisms, epidemiology, and consequences for treatment. Am. J. Med. 125, S3-S13. doi: 10.1016/j.amjmed.2011.11.001

Pfaller, M. A., Boyken, L., Hollis, R. J., Kroeger, J., Messer, S. A., Tendolkar, S., et al. (2008). In vitro susceptibility of invasive isolates of Candida spp. to anidulafungin, caspofungin, and micafungin: six years of global surveillance. J. Clin. Microbiol. 46, 150-156. doi: 10.1128/JCM.01901-07

Pfaller, M. A., Castanheira, M., Lockhart, S. R., Ahlquist, A. M., Messer, S. A., and Jones, R. N. (2012). Frequency of decreased susceptibility and resistance to echinocandins among fluconazole-resistant bloodstream isolates of Candida glabrata. J. Clin. Microbiol. 50, 1199-1203. doi: 10.1128/JCM.06112-11

Pfaller, M. A., and Diekema, D. J. (2007). Epidemiology of invasive candidiasis: a persistent public health problem. Clin. Microbiol. Rev. 20, 133-163. doi: 10.1128/CMR.00029-06
Pfaller, M. A., Messer, S. A., Boyken, L., Hollis, R. J., Rice, C., Tendolkar, S., et al. (2004). In vitro activities of voriconazole, posaconazole, and fluconazole against 4,169 clinical isolates of Candida spp. and Cryptococcus neoformans collected during 2001 and 2002 in the ARTEMIS global antifungal surveillance program. Diagn. Microbiol. Infect. Dis. 48, 201-205. doi: 10.1016/j.diagmicrobio.2003.09.008

Poss, Z. C., Ebmeier, C. C., and Taatjes, D. J. (2013). The Mediator complex and transcription regulation. Crit. Rev. Biochem. Mol. Biol. 48, 575-608. doi: 10.3109/10409238.2013.840259

Pound, M. W., Townsend, M. L., Dimondi, V., Wilson, D., and Drew, R. H. (2011). Overview of treatment options for invasive fungal infections. Med. Mycol. 49, 561-580. doi: 10.3109/13693786.2011.560197

Prasad, R., Dewergifosse, P., Goffeau, A., and Balzi, E. (1995). Molecular cloning and characterization of a novel gene of Candida albicans, CDR1, conferring multiple resistance to drugs and antifungals. Curr. Genet. 27, 320-329. doi: 10.1007/BF00352101

Prasad, R., and Goffeau, A. (2012). Yeast ATP-Binding cassette transporters conferring multidrug resistance. Annu. Rev. Microbiol. 39-63. doi: 10.1146/annurevmicro-092611-150111

Prasad, T., Saini, P., Gaur, N. A., Vishwakarma, R. A., Khan, L. A., Haq, Q. M., et al. (2005). Functional analysis of CaIPT1, a sphingolipid biosynthetic gene involved in multidrug resistance and morphogenesis of Candida albicans. Antimicrob. Agents Chemother. 49, 3442-3452. doi: 10.1128/AAC.49.8.34423452.2005

Pratt, W. B., and Toft, D. O. (1997). Steroid receptor interactions with heat shock protein and immunophilin chaperones. Endocr. Rev. 18, 306-360.

Prunuske, A. J., Waltner, J. K., Kuhn, P., Gu, B., and Craig, E. A. (2012). Role for the molecular chaperones Zuol and Sszl in quorum sensing via activation of the transcription factor Pdr1. Proc. Natl. Acad. Sci. U.S.A. 109, 472-477. doi: 10.1073/pnas.1119184109

Qiao, J., Liu, W., and Li, R. (2010). Truncated Afyap1 attenuates antifungal susceptibility of Aspergillus fumigatus to voriconazole and confers adaptation of the fungus to oxidative stress. Mycopathologia 170, 155-160. doi: 10.1007/s11046010-9309-2

Rajendran, R., Mowat, E., Mcculloch, E., Lappin, D. F., Jones, B., Lang, S., et al. (2011). Azole resistance of Aspergillus fumigatus biofilms is partly associated with efflux pump activity. Antimicrob. Agents Chemother. 55, 2092-2097. doi: 10.1128/AAC.01189-10

Rank, G. H., and Bech-Hansen, N. T. (1973). Single nuclear gene inherited cross resistance and collateral sensitivity to 17 inhibitors of mitochondrial function in Saccharomyces cerevisiae. Mol. Gen. Genet. 126, 93-102. doi: 10.1007/BF00330986

Rank, G. H., Gerlach, J. H., and Robertson, A. J. (1976). Some physiological alterations associated with pleiotropic cross resistance and collateral sensitivity in Saccharomyces cerevisiae. Mole. Gen. Genet. 144, 281-288. doi: 10.1007/BF00341726

Rank, G. H., Robertson, A. J., and Phillips, K. L. (1975). Modification and inheritance of pleiotropic cross resistance and collateral sensitivity in Saccharomcyes cerevisiae. Genetics 80, 783-793.

Redding, S. W., Kirkpatrick, W. R., Saville, S., Coco, B. J., White, W., Fothergill, A., et al. (2003). Multiple patterns of resistance to fluconazole in Candida glabrata isolates from a patient with oropharyngeal candidiasis receiving head and neck radiation. J. Clin. Microbiol. 41, 619-622. doi: 10.1128/JCM.41.2.619-622.2003

Richter, S. S., Galask, R. P., Messer, S. A., Hollis, R. J., Diekema, D. J., and Pfaller, M. A. (2005). Antifungal susceptibilities of Candida species causing vulvovaginitis and epidemiology of recurrent cases. J. Clin. Microbiol. 43, 2155-2162. doi: 10.1128/JCM.43.5.2155-2162.2005

Rodrigues-Pousada, C. A., Nevitt, T., Menezes, R., Azevedo, D., Pereira, J., and Amaral, C. (2004). Yeast activator proteins and stress response: an overview. FEBS Lett. 567, 80-85. doi: 10.1016/j.febslet.2004.03.119

Rognon, B., Kozovska, Z., Coste, A. T., Pardini, G., and Sanglard, D. (2006). Identification of promoter elements responsible for the regulation of MDR1 from Candida albicans, a major facilitator transporter involved in azole resistance. Microbiology 152, 3701-3722. doi: 10.1099/mic.0.29277-0

Rustad, T. R., Stevens, D. A., Pfaller, M. A., and White, T. C. (2002). Homozygosity at the Candida albicans MTL locus associated with azole resistance. Microbiology 148, 1061-1072.

Sanglard, D., Coste, A., and Ferrari, S. (2009). Antifungal drug resistance mechanisms in fungal pathogens from the perspective of transcriptional gene 
regulation. FEMS Yeast Res. 9, 1029-1050. doi: 10.1111/j.1567-1364.2009. 00578.x

Sanglard, D., Ischer, F., Monod, M., and Bille, J. (1997). Cloning of Candida albicans genes conferring resistance to azole antifungal agents: characterization of CDR2, a new multidrug ABC transporter gene. Microbiology 143, 405-416. doi: 10.1099/00221287-143-2-405

Sanglard, D., Kuchler, K., Ischer, F., Pagani, J. L., Monod, M., and Bille, J. (1995). Mechanisms of resistance to azole antifungal agents in Candida albicans isolates from AIDS patients involve specific multidrug transporters. Antimicrob. Agents Chemotherap. 40, 2378-2386. doi: 10.1128/AAC.39. 11.2378

Sanguinetti, M., Posteraro, B., Fiori, B., Ranno, S., Torelli, R., and Fadda, G. (2005). Mechanisms of azole resistance in clinical isolates of Candida glabrata collected during a hospital survey of antifungal resistance. Antimicrob. Agents Chemother. 49, 668-679. doi: 10.1128/AAC.49.2.668-679.2005

Sasse, C., Dunkel, N., Schafer, T., Schneider, S., Dierolf, F., Ohlsen, K., et al. (2012). The stepwise acquisition of fluconazole resistance mutations causes a gradual loss of fitness in Candida albicans. Mol. Microbiol. 86, 539-556. doi: 10.1111/j.1365-2958.2012.08210.x

Sasse, C., Schillig, R., Dierolf, F., Weyler, M., Schneider, S., Mogavero, S., et al. (2011). The transcription factor Ndt80 does not contribute to Mrr1-, Tac1-, and Upc2-mediated fluconazole resistance in Candida albicans. PLoS ONE 6:e25623. doi: 10.1371/journal.pone.0025623

Saunders, G. W., and Rank, G. H. (1982). Allelism of pleiotropic drug resistance in S. cerevisiae. Can. J. Genet. Cytol. 24, 493-502.

Schnell, N., Krems, B., and Entian, K.-D. (1992). The PAR1 (YAP1/SNQ3) gene of Saccharomyces cerevisiae, a c-jun homolog, is involved in oxygen metabolism. Curr. Genet. 21, 269-273. doi: 10.1007/BF00351681

Schubert, S., Barker, K. S., Znaidi, S., Schneider, S., Dierolf, F., Dunkel, N., et al. (2011a). Regulation of efflux pump expression and drug resistance by the transcription factors Mrr1, Upc2, and Cap1 in Candida albicans. Antimicrob. Agents Chemother. 55, 2212-2223. doi: 10.1128/AAC.01343-10

Schubert, S., Popp, C., Rogers, P. D., and Morschhauser, J. (2011b). Functional dissection of a Candida albicans zinc cluster transcription factor, the multidrug resistance regulator Mrr1. Eukaryot. Cell 10, 1110-1121. doi: 10.1128/EC. 05100-11

Schuetzer-Muehlbauer, M., Willinger, B., Krapf, G., Enzinger, S., Presterl, E., and Kuchler, K. (2003). The Candida albicans Cdr2p ATP-binding cassette (ABC) transporter confers resistance to caspofungin. Mol. Microbiol. 48, 225-235. doi: 10.1046/j.1365-2958.2003.03430.x

Selmecki, A., Gerami-Nejad, M., Paulson, C., Forche, A., and Berman, J. (2008). An isochromosome confers drug resistance in vivo by amplification of two genes, ERG11 and TAC1. Mol. Microbiol. 68, 624-641. doi: 10.1111/j.13652958.2008.06176.x

Shahi, P., Gulshan, K., and Moye-Rowley, W. S. (2007). Negative transcriptional regulation of multidrug resistance gene expression by an Hsp70 protein. J. Biol. Chem. 282, 26822-26831. doi: 10.1074/jbc.M704772200

Shahi, P., Gulshan, K., Naar, A. M., and Moye-Rowley, W. S. (2010). Differential roles of transcriptional mediator subunits in regulation of multidrug resistance gene expression in Saccharomyces cerevisiae. Mol. Biol. Cell 21, 2469-2482. doi: 10.1091/mbc.E09-10-0899

Simonics, T., Kozovska, Z., Michalkova-Papajova, D., Delahodde, A., Jacq, C., and Subik, J. (2000). Isolation and molecular characterization of the carboxyterminal pdr3 mutants in Saccharomyces cerevisiae. Curr. Genet. 38, 248-255. doi: $10.1007 / \mathrm{s} 002940000164$

Slaven, J. W., Anderson, M. J., Sanglard, D., Dixon, G. K., Bille, J., Roberts, I. S., et al. (2002). Increased expression of a novel Aspergillus fumigatus ABC transporter gene, atrF, in the presence of itraconazole in an itraconazole resistant clinical isolate. Fungal Genet. Biol. 36, 199-206. doi: 10.1016/S1087-1845(02) 00016-6

Snelders, E., Van Der Lee, H. A., Kuijpers, J., Rijs, A. J., Varga, J., Samson, R. A., et al. (2008). Emergence of azole resistance in Aspergillus fumigatus and spread of a single resistance mechanism. PLoS Med. 5:e219. doi: 10.1371/journal.pmed.0050219

Steier, Z., Vermitsky, J. P., Toner, G., Gygax, S. E., Edlind, T., and Katiyar, S. (2013). Flucytosine antagonism of azole activity versus Candida glabrata: role of transcription factor Pdr1 and multidrug transporter Cdr1. Antimicrob. Agents Chemother. 57, 5543-5547. doi: 10.1128/AAC. 02394-12
Szakacs, G., Paterson, J. K., Ludwig, J. A., Booth-Genthe, C., and Gottesman, M. M. (2006). Targeting multidrug resistance in cancer. Nat. Rev. Drug Discov. 5, 219-234. doi: 10.1038/nrd1984

Sze, J. Y., Remboutsika, E., and Kohlhaw, G. B. (1993). Transcriptional regulator Leu3 of Saccharomyces cerevisiae: separation of activator and repressor functions. Mol. Cell. Biol. 13, 5702-5709.

Te Dorsthorst, D. T., Verweij, P. E., Meletiadis, J., Bergervoet, M., Punt, N. C., Meis, J. F., et al. (2002). In vitro interaction of flucytosine combined with amphotericin $\mathrm{B}$ or fluconazole against thirty-five yeast isolates determined by both the fractional inhibitory concentration index and the response surface approach. Antimicrob. Agents Chemother. 46, 2982-2989. doi: 10.1128/AAC.46.9.29822989.2002

Teixeira, M. C., Dias, P. J., Simoes, T., and Sa-Correia, I. (2008). Yeast adaptation to mancozeb involves the up-regulation of FLR1 under the coordinate control of Yap1, Rpn4, Pdr3, and Yrr1. Biochem. Biophys. Res. Commun. 367, 249-255. doi: 10.1016/j.bbrc.2007.12.056

Thakur, J. K., Arthanari, H., Yang, F., Pan, S.-J., Fan, X., Breger, J., et al. (2008). A nuclear receptor-like pathway regulating multidrug resistance in fungi. Nature 452, 604-609. doi: 10.1038/nature06836

Toone, W. M., Morgan, B. A., and Jones, N. (2001). Redox control of AP-1-like factors in yeast and beyond. Oncogene 20, 2336-2346. doi: 10.1038/sj.onc.1204384

Torelli, R., Posteraro, B., Ferrari, S., La Sorda, M., Fadda, G., Sanglard, D., et al. (2008). The ATP-binding cassette transporter-encoding gene CgSNQ2 is contributing to the CgPDR1-dependent azole resistance of Candida glabrata. Mol. Microbiol. 68, 186-201. doi: 10.1111/j.1365-2958.2008.06143.x

Traven, A., Wong, J. M., Xu, D., Sopta, M., and Ingles, C. J. (2001). Interorganellar communication. Altered nuclear gene expression profiles in a yeast mitochondrial DNA mutant. J. Biol. Chem. 276, 4020-4027. doi: 10.1074/jbc.M006 807200

Tsai, H. F., Krol, A. A., Sarti, K. E., and Bennett, J. E. (2006). Candida glabrata PDR1, a transcriptional regulator of a pleiotropic drug resistance network, mediates azole resistance in clinical isolates and petite mutants. Antimicrob. Agents Chemother. 50, 1384-1392. doi: 10.1128/AAC.50.4.1384-1392.2006

Van Den Hazel, H. B., Pichler, H., Do Valle Matta, M. A., Leitner, E., Goffeau, A., and Daum, G. (1999). PDR16 and PDR17, two homologous genes of Saccharomyces cerevisiae, affect lipid biosynthesis and resistance to multiple drugs. J. Biol. Chem. 274, 1934-1941. doi: 10.1074/jbc.274.4.1934

Van Der Linden, J. W., Snelders, E., Kampinga, G. A., Rijnders, B. J., Mattsson, E., Debets-Ossenkopp, Y. J., et al. (2011). Clinical implications of azole resistance in Aspergillus fumigatus, The Netherlands, 2007-2009. Emerging Infect. Dis. 17, 1846-1854. doi: 10.3201/eid1710.110226

Vermitsky, J. P., and Edlind, T. D. (2004). Azole resistance in Candida glabrata: coordinate upregulation of multidrug transporters and evidence for a Pdr1like transcription factor. Antimicrob. Agents Chemother. 48, 3773-3781. doi: 10.1128/AAC.48.10.3773-3781.2004

Voelker, D. R. (1997). Phosphatidylserine decarboxylase. Biochim. Biophys. Acta 1348, 236-244. doi: 10.1016/S0005-2760(97)00101-X

White, T. C. (1997). Increased mRNA levels of ERG16, CDR and MDR1 correlate with increases in azole resistance in Candida albicans isolates from a patient infected with human immunodeficiency virus. Antimicrob. Agents Chemother. 41, 1482-1487.

Wirsching, S., Michel, S., and Morschhauser, J. (2000). Targeted gene disruption in Candida albicans wild-type strains: the role of the MDR1 gene in fluconazole resistance of clinical Candida albicans isolates. Mol. Microbiol. 36, 856-865. doi: 10.1046/j.1365-2958.2000.01899.x

Wu, A., Wemmie, J. A., Edgington, N. P., Goebl, M., Guevara, J. L., and MoyeRowley, W. S. (1993). Yeast bZIP proteins mediate pleiotropic drug and metal resistance. J. Biol. Chem. 268, 18850-18858.

Zhang, L., Hach, A., and Wang, C. (1998). Molecular mechanism governing heme signaling in yeast: a higher-order complex mediates heme regulation of the transcriptional activator HAP1. Mol. Cell. Biol. 18, 3819-3828.

Zhang, X., Cui, Z., Miyakawa, T., and Moye-Rowley, W. S. (2001). Crosstalk between transcriptional regulators of multidrug resistance in Saccharomyces cerevisiae. J. Biol. Chem. 276, 8812-8819. doi: 10.1074/jbc.M010 686200

Zhang, X., Kolaczkowska, A., Devaux, F., Panwar, S. L., Hallstrom, T. C., Jacq, C., et al. (2005). Transcriptional regulation by Lgelp requires a function independent of its role in histone H2B ubiquitination. J. Biol. Chem. 280, 2759-2770. doi: 10.1074/jbc.M408333200 
Zhang, X., and Moye-Rowley, W. S. (2001). Saccharomyces cerevisiae multidrug resistance gene expression inversely correlates with the status of the Fo component of the mitochondrial ATPase. J. Biol. Chem. 276, 47844-47852. doi: 10.1074/jbc.M106285200

Znaidi, S., De Deken, X., Weber, S., Rigby, T., Nantel, A., and Raymond, M. (2007). The zinc cluster transcription factor Taclp regulates PDR16 expression in Candida albicans. Mol. Microbiol. 66, 440-452. doi: 10.1111/j.13652958.2007.05931.x

Conflict of Interest Statement: The authors declare that the research was conducted in the absence of any commercial or financial relationships that could be construed as a potential conflict of interest.
Received: 25 February 2014; accepted: 25 March 2014; published online: 16 April 2014. Citation: Paul S and Moye-Rowley WS (2014) Multidrug resistance in fungi: regulation of transporter-encoding gene expression. Front. Physiol. 5:143. doi: 10.3389/fphys. 2014.00143

This article was submitted to Membrane Physiology and Membrane Biophysics, a section of the journal Frontiers in Physiology.

Copyright (C) 2014 Paul and Moye-Rowley. This is an open-access article distributed under the terms of the Creative Commons Attribution License (CC BY). The use, distribution or reproduction in other forums is permitted, provided the original author(s) or licensor are credited and that the original publication in this journal is cited, in accordance with accepted academic practice. No use, distribution or reproduction is permitted which does not comply with these terms. 